\title{
Pongamia Pinnata (PP) shell powder filled sisal/kevlar hybrid composites: Physico-Mechanical and Morphological Characteristics
}

\section{J Praveenkumara}

UVCE: University Visveswarayya College of Engineering

\section{Vidya Sagar H N}

University Visvesvaraya College of Engineering

\section{P Madhu}

Malnad College of Engineering

\section{Yashas Gowda}

King Mongkut's Institute of Technology North Bangkok: King Mongkut's University of Technology North Bangkok

\section{Sanjay Mavinkere Rangappa ( $\sim$ mcemrs@gmail.com )}

King Mongkut's University of Technology North Bangkok https://orcid.org/0000-0001-8745-9532

\section{Mohammad Rizwan Khan}

King Saud University

Imran Khan

Aligarh Muslim University

\section{Suchart Siengchin}

King Mongkut's Institute of Technology North Bangkok: King Mongkut's University of Technology North Bangkok

\section{Research Article}

Keywords: Sisal, Kevlar, Pongamia pinnata (PP) shell powder, epoxy, SEM

Posted Date: March 11th, 2021

DOl: https://doi.org/10.21203/rs.3.rs-273651/v1

License: (c) (i) This work is licensed under a Creative Commons Attribution 4.0 International License.

Read Full License 


\section{Pongamia Pinnata (PP) shell powder filled sisal/kevlar hybrid composites:}

\section{Physico-Mechanical and Morphological Characteristics}

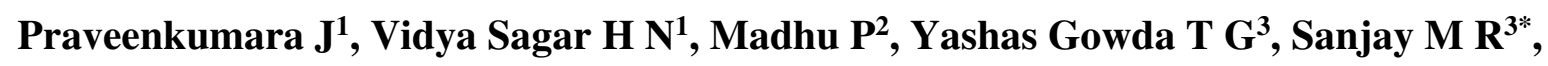 Mohammad Rizwan Khan ${ }^{4}$, Imran Khan ${ }^{5}$, Suchart Siengchin ${ }^{3}$}

${ }^{1}$ Department of Mechanical Engineering, University Visvesvaraya College of Engineering, Bangalore University, Bangalore, India.

${ }^{2}$ Department of Mechanical Engineering, Malnad College of Engineering, Hassan, Visvesvaraya Technological University, Belagavi, Karnataka, India.

${ }^{3}$ Natural Composites Research Group Lab, Department of Materials and Production Engineering, The Sirindhorn International Thai-German Graduate School of Engineering, King Mongkut's University of Technology North Bangkok, Thailand.

${ }^{4}$ Department of Chemistry, College of Science, King Saud University, Riyadh 11451, Saudi Arabia.

${ }^{5}$ Applied Sciences and Humanities Section, University Polytechnic, Faculty of Engineering and Technology, Aligarh Muslim University, Aligarh - 202002, India.

*Corresponding Author: mcemrs@gmail.com 
ABSTRACT: The composite industry is attracted by natural fiber reinforced polymer materials for various valuable engineering applications due to its eco-friendly nature, less cost, enhanced mechanical properties and thermal properties. This present work aimed at incorporating sisal and kevlar woven fabrics with the epoxy matrix and to study the effect of pongamia pinnata shell powder on this sisal/ kevlar hybrid composites. The six different laminates were prepared using hand lay-up method with filler percentage varying $2 \%, 4 \%$ and $6 \%$. The prepared laminates cut according to ASTM standards for performing different mechanical tests. Results reveal that reduction of void percentage was observed at higher filler contents, while the incorporation of kevlar fiber enhances the impact, tensile strength and tensile modulus values. The flexural strength and inter laminar shear strength were higher for $2 \%$ filler composites, while the highest flexural modulus, hardness values were observed for $6 \%$ filler filled composites. The water absorption percentage was maximum for sisal laminate (L-1) and minimum for kevlar laminate L-2. The fractured tensile and flexural specimens were analyzed using scanning electron microscope (SEM).

KEYWORDS: Sisal, Kevlar, Pongamia pinnata (PP) shell powder, epoxy, SEM

\section{INTRODUCTION}

Natural fiber composites are the new class of engineering materials in composite industry which are preferably used as lightweight, structural and semi-structural components in automotive, constructional and building applications (Arpitha et al. 2017; Sanjay et al. 2018). These natural fibers are the promising materials especially preferred in composite materials to replace synthetic materials either partially or fully due to affordable class properties, biodegradability, lower weight, good mechanical properties and renewable sources of materials (Gowda et al. 2018; Madhu et al. 2019; Jothibasu et al. 2020). The plants which are the sources of natural fibers are distinguished into two categories based on their applications. 
The first category of plants such as hemp, jute etc., are utilized only for the extraction of fibers, while the second category of plants such as pineapple, banana etc., are grown for fruit farming and their byproducts and are used for extraction of fibers (Sanjay et al. 2019). Some of the commonly used natural fibers include flax, kenaf, ramie, roselle, urena (bast fibers), sisal, palm, bagasse, bamboo, coir, cotton, kapok (seed-hair and other fibers) (Elanchezhian et al. 2018; Thyavihalli Girijappa et al. 2019; Vinod et al. 2020). Sisal fiber belongs to the Agave sisalana plant and their fibers are extracted from the leaves of this plant. The sisal fiber cultivation was done by Maya, Indians and then by the Europeans and Brazil is the highest sisal fiber producer country in the world. The major advantage of sisal fiber plant is it can grow in any environment with any type of soil, highly potential, hard fiber and its yearly percentage of production is high as compared to total textile production. Each sisal fiber leaves consists of $87.25 \%$ moisture, $4 \%$ fiber, $0.75 \%$ cuticle and $8 \%$ dry matter (Rana et al. 2017; Damião Xavier et al. 2018; Naveen et al. 2019). Natural fibers are not having enough properties to be used as prospective materials for high potential applications. To overcome the negative aspects of natural reinforcements, the synthetic materials are preferred along with natural fibers and synthetic fibers such as glass, carbon and kevlar fibers are the most recognized materials from past few decades to be hybridized with various natural fibers. Kevlar is one of the strongest, lightweight and heat resistant synthetic materials related to one kind of aramid fibers. It has high tensile strength, tensile modulus, toughness and chemically stable properties. It finds its applications in composite materials, aerospace engineering, bulletproof materials and automotive parts (Fu et al. 2018; Amir et al. 2019). The method of combining two or more types of fibers in a single matrix is termed as hybridization. This efficient strategy increases the mechanical properties of the composites. The finer balancing of mechanical properties are found in hybrid composites in comparison with non-hybrid composites (Swolfs et al. 2014; Asim et al. 2017). Based on the requirement of properties and 
type of applications different types of natural and synthetic fillers are used for enhancing the properties of hybridized natural-synthetic composites. Natural fillers are bio-waste products and some of the examples are eggshells, rice husk, coconut shell powder, peanut shell powder, pongamia pinnata shell powder, fish bone and fish scale fillers. These natural fillers increase the modulus, biodegradability and correspondingly decrease the composite cost and matrix ductility. The polymer composites filled with natural fillers provides application in several mechanical, tribological and industrial sectors (Mohan et al. 2012; Shakuntala et al. 2014; Jani et al. 2016).

S. Dinesh et al. conducted an experiment on wood dust filled jute fiber reinforced epoxy composites. The proper distribution of wood dust particles and better adhesion with the matrix resulted in improved mechanical properties. The water absorption percentage was less in wood dust filled composite during 27 days of experiment (Dinesh et al. 2020). H. Singh et al. studied the properties of fish bone powder (FBP) filled jute/carbon hybrid composites under varying 0 - 5 wt. \% of FBP powder. Addition of filler increased the contact surface area and good adhesive nature resulting in enhanced tensile properties whereas flexural strength showed declination value due to the ductility induced in the matrix which was caused mainly because of filler material addition. The micro-hardness value diminished by weak bonding occurring between fiber and matrix owing to less uniform distribution of filler (Singh et al. 2020). V. Sharma et al. investigated the effect of fly ash particles (5\%, 10\% and $15 \%)$ on basalt fiber reinforced epoxy composites. The tensile, flexural and impact properties are increased for $10 \mathrm{wt}$. \% of filler whereas decreased for the filler wt. \% from 10 to $15 \%$. As the filler weight increased, it was noticeable that the matrix was unable to transfer the load effectively to the reinforcement (Sharma et al. 2020). Khalil et al. documented that the optimum value of mechanical properties showed high density for 3 wt. \% of coconut shell filler filled kenaf/coconut fiber reinforced composites. This was due to incorporation of high- 
density filler in low density matrix which resulted in the reduction of void content and enhanced strength of the composites (HPS et al. 2017). Praveenkumara et al. incorporated $\mathrm{SiC}$ particles in bamboo/carbon reinforced epoxy composites and reported that the prepared composites showed higher tensile and hardness values as opposed to synthetic laminates and indicated low water absorption in comparison with pure natural fiber laminates (Praveenkumara et al. 2017). Prabu et al. documented that the red mud incorporated sisal/banana fiber reinforced polyester composites revealed better flexural and impact strength due to higher load withstanding capacity, while the tensile strength reduced because of negligible stress interface between filler and matrix materials (Prabu et al. 2012). Matykiewicz et al. investigated the mechanical and thermal properties of basalt powder filled basalt fiber reinforced epoxy composites using hand lay-up method. The addition of 2.5 wt. $\%$ basalt powder gives better stiffness and thermal resistive property to the prepared composites. The tensile strength and modulus were higher whereas, the flexural strength decreased for 2.5 wt. \% filler laminate (Matykiewicz et al. 2017).

From the current literature survey, it is concluded that although many researchers have worked on the hybridization of natural/synthetic hybrid composite and studied the effect of natural fillers on these hybrid composites there are no works till date deliberated on pongamia pinnata shell (PPS) powder filled sisal/kevlar hybrid composites. Thus, the present study deals with the study of both hybridization and PPS filler material effect on sisal/ kevlar hybrid composites. The void and weight percentage, mechanical properties (tensile, flexural, impact, inter-laminar shear strength and hardness behavior) and water absorption studies have been carried out to evaluate the prepared hybrid composites. Also, the micro structural analysis of the fractured tensile and flexural specimens was scrutinized using scanning electron microscopy (SEM). 
MATERIALS AND METHODS

127 In this present work, sisal and kevlar fibers are used as reinforcement materials and were 128 purchased from Go Green Products, Chennai, Tamilnadu and Composites Tomorrow, 129 Vadodara, Gujarat respectively. The parameters of sisal and kevlar fibers are tabulated in Table 1. Epoxy resin CT/E-556 and CT/AH-951 polyamine hardener was also purchased from Composites Tomorrow, Vadodara, Gujarat. For the matrix phase preparation epoxy and hardener were mixed in 10:1 ratio. The bidirectional macroscopic view of sisal and kevlar fabric are shown in Figure 1 (a \& b). Pongamia Pinnata shells were collected Pongame oil tree and then seeds were removed from the shells which were later dried for 3-4 days in the sun light. After the removal of moisture content, the shells were grinded to powder form. Figure 1 (c \& d) illustrates the pongamia pinnata shells (PPS) and PPS powder.

Table 1. Physical parameters of sisal and Kevlar fabrics

\begin{tabular}{|l|l|l|}
\hline Parameters & Sisal & Kevlar \\
\hline Woven style & Plain & Plain \\
\hline Density (g/cc) & 1.36 & 1.43 \\
\hline Weight (gsm) & 160 & 220 \\
\hline Thickness (mm) & 0.48 & 0.52 \\
\hline Warp yarns (yarns/m) & 810 & 600 \\
\hline Weft yarns (yarns/m) & 810 & 600 \\
\hline
\end{tabular}




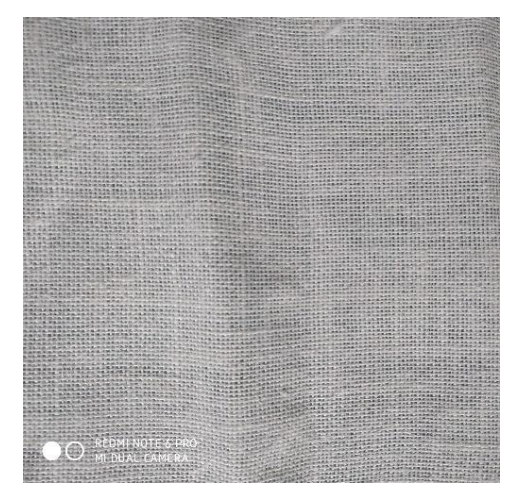

(a)

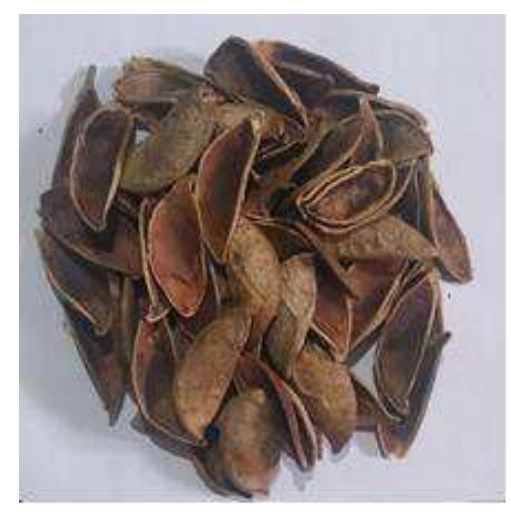

(c)

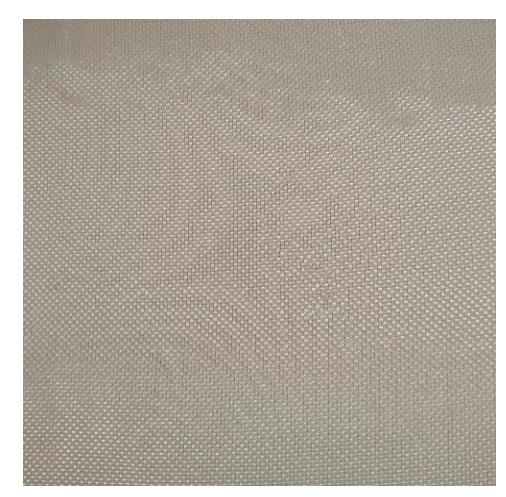

(b)

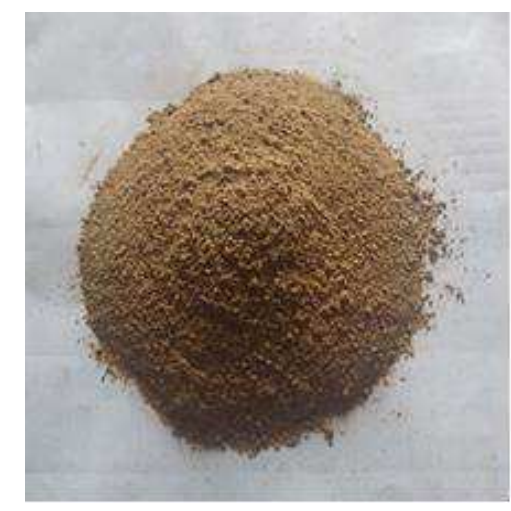

(d)

140 Figure 1. Materials used in the present study: (a) sisal fabric (b) kevlar fabric (c) Pongamia

141 pinnata shells (d) Pongamia pinnata shells powder

\subsection{PREPARATION OF COMPOSITE LAMINATES}

144 The composites of sisal, kevlar and PP filled laminates were fabricated using hand lay-up method (Figure 2). The six types of different laminates of size $250 \times 250 \mathrm{~mm}^{2}$ with total 4 layers of fabrics for each laminate has been maintained to achieve the thickness of $3 \mathrm{~mm}$ with alternative sisal and kevlar fabric lay-up. The filler material was mixed with matrix phase by the amount of 2, 4 and 6 wt. \%. The sequence of fabric arranged along with weight fraction percentage and volume fraction is as shown in Table 2. Granite slab is used as a flat mold surface for the fabrication of laminates. Initially, silicone spray was sprayed on the bottom, 
top and inner sides of the mold surfaces. Next, as per the laminate sequence, the fabrics were

152

153

154

155

156

157

158

159 placed on the mold surface one by one by applying the epoxy uniformly using brushes and by the roller movements on the fabric to avoid the void formation. After completion of fabric lay-up, a wooden board of the mold size was placed along with the dead weights on the mold surface for the duration of 2 days. After 2 days in order to remove the moisture content, the laminates were placed inside the electric oven at $70^{\circ} \mathrm{C}$ for 24 hours. Later the laminates were taken out from the oven and cut into ASTM standard dimensions for mechanical testing.

In Table 2, $\mathrm{w}_{\mathrm{f}}$ indicates the weight of the fabric \{weight of sisal fabric ( $\mathrm{w}_{\mathrm{s}}$ ) is $17 \pm 1 \mathrm{~g}$, weight of kevlar fabric $\left(\mathrm{wf}_{\mathrm{f}}\right)$ is $15 \pm 1 \mathrm{~g}$ for the $250 \times 250 \mathrm{~mm}^{2}$ dimension fabric , $\mathrm{wm}_{\mathrm{m}}$ indicates the weight of the matrix phase, $\mathrm{w}_{\mathrm{pps}}$ is the weight of filler material. $\mathrm{W}_{\mathrm{f}}$ is the weight fraction of fabric $\left\{\mathrm{Ws}\right.$ indicates weight fraction of sisal, $\mathrm{W}_{\mathrm{k}}$ indicates weight fraction of kevlar $\}, \mathrm{W}_{\mathrm{m}}$ is the matrix phase weight fraction, $\mathrm{w}_{\mathrm{pp}}$ is the weight fraction of filler material.

Table 2. Laminates sequence with weight and volume fraction

\begin{tabular}{|c|c|c|c|c|c|c|c|c|c|c|}
\hline \multirow{3}{*}{ Laminates } & \multirow{3}{*}{$\begin{array}{l}\text { Stacking } \\
\text { sequence }\end{array}$} & \multicolumn{4}{|c|}{ Weight (g) } & \multicolumn{4}{|c|}{ Weight fraction (\%) } & \multirow{3}{*}{$\begin{array}{l}\text { Volume } \\
\text { fraction } \\
(\%)\end{array}$} \\
\hline & & \multicolumn{3}{|l|}{$\mathbf{w}_{\mathbf{f}}$} & \multirow[b]{2}{*}{$\mathbf{w}_{\mathbf{m}}$} & \multicolumn{3}{|l|}{$\mathbf{W}_{\mathrm{f}}$} & \multirow{2}{*}{$\mathbf{W}$} & \\
\hline & & $\mathbf{w}_{\mathbf{s}}$ & $\mathbf{w}_{\mathbf{k}}$ & $\mathbf{w}_{\mathrm{pp}}$ & & $\mathbf{W}_{\mathrm{s}}$ & $\mathbf{W}_{\mathbf{k}}$ & $\begin{array}{l}\text { W } \\
\text { pp }\end{array}$ & & \\
\hline L-1 & $\mathrm{S}+\mathrm{S}+\mathrm{S}+\mathrm{S}$ & $\begin{array}{l}70 \pm \\
3\end{array}$ & - & - & $\begin{array}{l}170 \\
\pm 8\end{array}$ & $\begin{array}{l}29 . \\
17\end{array}$ & - & - & $\begin{array}{l}7 \\
0\end{array}$ & 27.44 \\
\hline L-2 & $\mathrm{K}+\mathrm{K}+\mathrm{K}+\mathrm{K}$ & - & $60 \pm$ & - & 140 & - & 30 & - & 7 & 27.25 \\
\hline
\end{tabular}






- S -Sisal fabric, K - kevlar fabric, PP - pongamia pinnata shell powder 

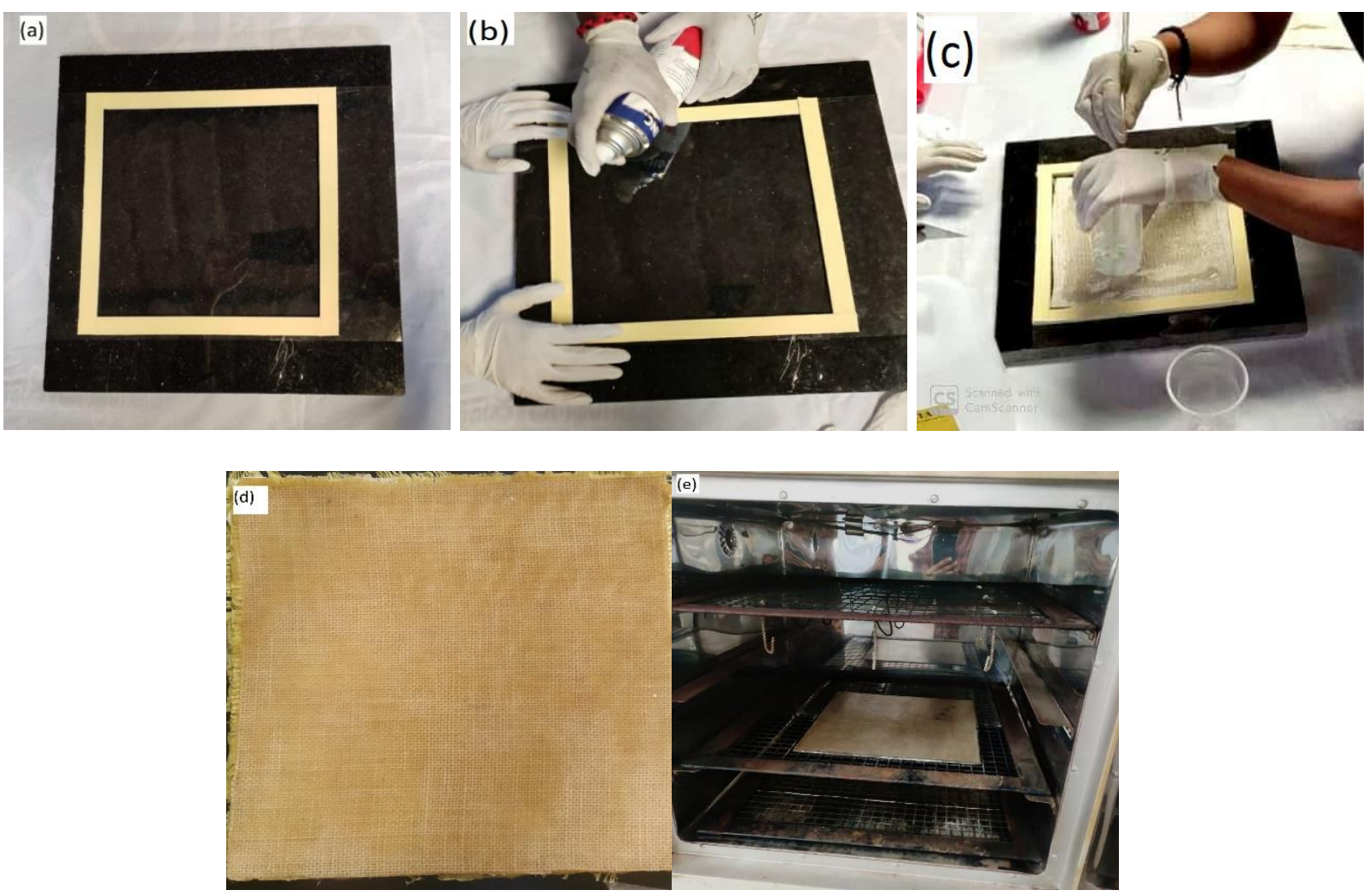

Figure 2. (a) Mold prepared using sealing tape (b) Silicone spray (c) Resin lay up (d)

Fabricated laminate (e) Laminate curing in oven.

\section{EXPERIMENTAL STUDIES}

\section{DENSITY AND VOID FRACTION STUDIES}

The laminates were prepared according to ASTM D2734-94 method to find out the density and void percentage of the prepared hybrid composites. The experimental density was 
181

182

183

184

185

186

187

188

189

190

191

192

193

194

195

196

197

198

199

200

201

202

203

liquid. The equation (3) was used for the calculation of experimental density (Ojha et al. 2014).

$$
\rho_{e x}=\frac{w_{a}}{w_{a}-w_{I}} \times \rho_{u}
$$

Where $\rho_{e x}$ represents experimental density, $w_{a}$ represents weight of the specimen in air, $w_{l}$ represents weight in liquid and $\rho_{l}$ indicates density of the liquid.

The theoretical density was calculated for each laminate and six trials were conducted for the individual laminates and middle value was recorded. The theoretical density was calculated based on weight fraction using the equation (4) (Rajulu et al. 2004).

$$
\rho_{t h}=\frac{100}{\frac{W_{m}}{\rho_{m}}+\frac{W_{f}}{\rho_{f}}}
$$

Where $W_{m}$ indicates the weight fraction $\%$ of matrix phase, $\rho_{m}$ represents the density of the matrix phase, $W_{f}$ indicates weight fraction $\%$ of fiber and $\rho_{f}$ indicates density of the fabric.

During the fabrication of composites, voids were induced due to the improper fabrication technique. The composite with below $1 \%$ voids is considered to be a good composite, while the laminates greater than $5 \%$ are considered to be poor ones. As the void percentage increases the properties of the composite show diminished values with lessening waterresistant property. The density and void fraction percentage is tabulated in Table 3 . The void percentage was calculated using theoretical and experimental density using equation (5) (Arpitha et al. 2017) ${ }^{[29]}$.

$$
V_{V}=\frac{\rho_{t h}-\rho_{E x}}{\rho_{t h}}
$$

Where $\mathrm{v}_{\mathrm{v}}$ indicates void percentage, $\rho_{t h}$ indicates theoretical density and $\rho_{\operatorname{ex}}$ indicates experimental density. 
Table 3. Density and void fraction of laminates

\begin{tabular}{|l|c|l|c|}
\hline Laminates & Theoretical density & Experimental & Void (\%) \\
& $\rho_{\text {th }}(\mathbf{g} / \mathbf{c c})$ & density $\rho_{\text {ex }}(\mathbf{g} / \mathbf{c c})$ & \\
\hline L-1 & 1.299 & 1.289 & 0.76 \\
\hline L-2 & 1.306 & 1.302 & 0.45 \\
\hline L-3 & 1.223 & 1.215 & 0.65 \\
\hline L-4 & 1.192 & 1.185 & 0.58 \\
\hline L-5 & 1.168 & 1.162 & 0.51 \\
\hline L-6 & 1.113 & 1.108 & 0.44 \\
\hline
\end{tabular}

\section{TENSILE STRENGTH STUDIES}

The tensile strength and tensile modulus were calculated according to the ASTM D638-03 testing machine (UTM) with a load cell capacity of $1000 \mathrm{Kg}$. The tests were conducted for six trials for each laminate under a fixed strain rate of $3 \mathrm{~mm} / \mathrm{min}$. S1 (a) and (b) envies the specimen before and after the test. Initially, the specimen was fixed in between the grippers provided and the deflections were noted down for each corresponding load. The load was applied till the specimen broke and the break load was noted for the calculation of ultimate strength of the composite.

\section{FLEXURAL STRENGTH STUDIES}

218 The flexural strength and flexural modulus were calculated as per ASTM D790-07 standard with a dimension of $90 \times 10 \times 3 \mathrm{~mm}^{3}$ using a same UTM machine. The three-point bending method was used with a constant strain rate of $1.15 \mathrm{~mm} / \mathrm{min}$. The flexural specimen before 
and after test is shown in $\mathbf{S 2}$ (a) and (b). For this test also six identical specimens were taken

222 from each laminate. The load was applied at the center of the gauge length and the ends were supported by gripped jaws. Corresponding load v/s displacement and stress v/s strain graphs were obtained.

\section{IMPACT STRENGTH STUDIES}

227 The impact strength of the laminates was carried out by computerized impact tester according to ASTM D256 standard with a dimension $63 \times 12.7 \times 3 \mathrm{~mm}^{3}$. The impact test specimen was loaded in grippers of the impact tester and the amount of energy absorbed for the fracture of specimen was recorded in joules. S3 (a) and (b) shows impact test specimens before and after test.

\section{INTER-LAMINAR SHEAR STRENGTH (ILSS) STUDIES}

The ILSS test also called as short beam shear test (SBS) is one of the quality measures for brittle matrix-based composites. This test was conducted as per ASTM D2344 standard with specimen dimensions of $60 \times 10 \times 3 \mathrm{~mm}^{3}$. The specimen was placed between the two supports and the load is applied to the center of span length using three-point bending method. During the loading of specimen, the shear stress exerts on the laminates and loaddisplacement, stress-strain graphs were obtained at a loading rate of $1.15 \mathrm{~mm} / \mathrm{min}$. The ILSS specimens before and after test are illustrated in S4 (a) and (b). The ILSS strength was calculated using peak load of the specimen.

\section{HARDNESS STUDIES}

244 The hardness of the specimen was obtained using a digital Shore-D hardness durometer. The range of durometer is $0-100 \mathrm{HD}$ with a step of $0.5 \mathrm{HD}$. It is specially used for testing the 
hardness of polymer, plastics and rubbers. During testing, the durometer was pressed on the

247 surface, then the indenter pin penetrates the specimen and resistance to indentation was displayed in digital form (Qi et al. 2003). If the HD value is above 60, it is considered as good resilience material and below 60 is considered as poor resilience material.

\section{WATER ABSORPTION STUDIES}

252

253

254

255

256

257

258

259

260

261

262

263

264

265

266

267

268

269

270 9

The water absorption test was conducted by immersing the specimens under normal and distilled water condition in the duration of 28 days. The test specimens were prepared as per ASTM D570 standard with dimensions $30 \times 28 \times 3 \mathrm{~mm}^{3}$. The specimens are shown in S5. The specimen weights are measured in the interval of 7 days by removing the water molecules on the specimen surface and weighed using precise digital balance. The water absorption percentage was calculated using the equation (6) (Sanjay et al. 2016).

$$
\text { Water absorption }(\%)=\frac{w_{b}-w_{a}}{w_{a}} \times 100
$$

where $W_{b}$ is the weight of the specimen after 7 days of immersion and $W_{\alpha}$ is the weight of the specimen before immersion.

\section{SCANNING ELECTRON MICROSCOPY (SEM) STUDIES}

The fractured surfaces of tensile and flexural specimens were studied by using Hitachi SU 3500 model SEM equipment. The ends of the fractured specimens were cut into less than 10 $\times 10 \times 3 \mathrm{~mm}^{3}$ dimensions and their surfaces were uniformly coated with carbon and gold. The morphology tests were carried out for the identification of voids, fiber pull-out in the composite, voids, fiber-matrix interface, uniform mixing of filler contents in the matrix and to understand the adhesive property behaviour between the reinforcement and matrix phase. 


\section{RESULTS AND DISCUSSIONS}

\section{DENSITY AND VOID FRACTION}

273

274

The volume fraction (\%) of voids in the composite laminate was obtained by the difference of experimental and theoretical densities. A slight difference of theoretical and experimental densities was observed in laminates. The laminate L-6 shows a lesser amount of voids $(0.44 \%)$ as compared to other laminates due to higher compatibility between reinforcement, matrix and filler material. The laminate L-2 has $0.45 \%$ of voids which was slightly higher than laminate L-2. The laminate L-1 contains $0.76 \%$ of voids fraction and was comprised of only natural reinforcement. The six different composite laminates void fraction ranged between 0 to $1 \%$. This indicates that all composites were properly fabricated with acceptable void percentage. By considering above test observations, it is concluded that the affiliation of synthetic reinforcement and higher concentration of filler material reduces the void percentage and leads to augmentation in properties.

\section{TENSILE STRENGTH ANALYSIS}

The tensile properties of laminates L-1, L-2, L-3, L-4, L-5 and L-6 were studied using UTM machine according to ASTM standard. The stress v/s strain curves for different laminates are shown in S6. The laminate L-2 has higher yield stress as compared to other laminates and the laminate L-1 has lower stress yield capacity. Laminate L-3 reaches second highest stress value next to the L-2. Among PP filled composites, L-4 having $2 \%$ filler yields higher stress value while its stress value decreased for L-5 and L-6. The tensile strength and tensile modulus of different laminates were obtained by stress-strain raw data. Similarly load v/s displacement graph was obtained and the same as been shown in S7. The composite having only kevlar reinforcement (L-2) withstands higher tensile strength of $134.96 \mathrm{MPa}$ and modulus of $899.7 \mathrm{MPa}$. L-2 laminate which contains only natural sisal reinforcement 
achieves tensile strength of $48.96 \mathrm{MPa}$ and modulus of $661.62 \mathrm{MPa}$. The hybridized

297

298

299

300

301

302

303

304

305

306

307

308

309

310

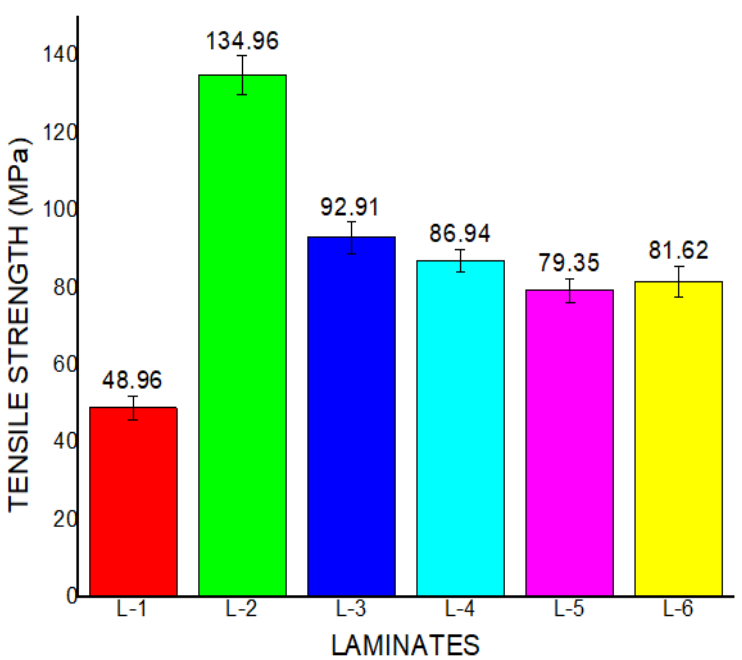

(a)

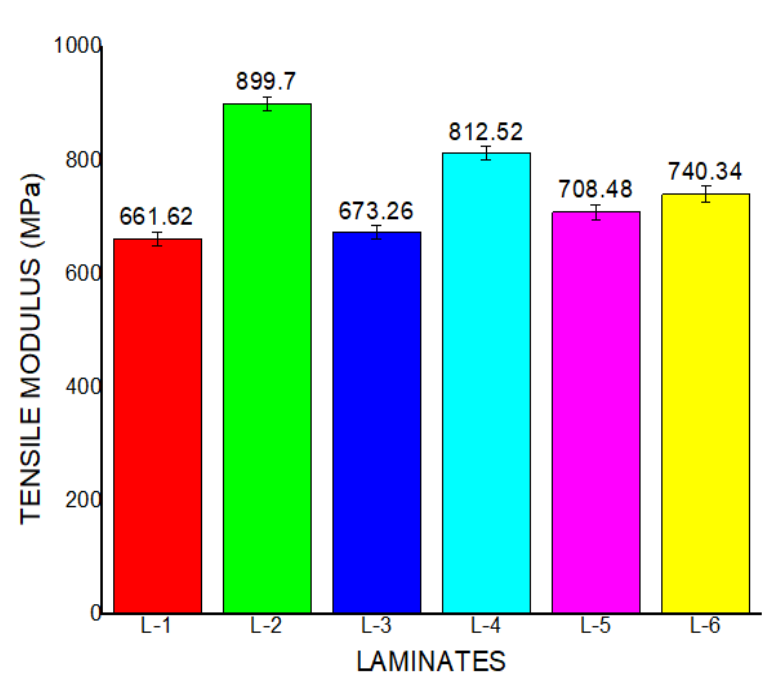

(b)

311 Figure 3. Tensile test results of the laminates: (a) Tensile strength (b) Tensile modulus 


\section{FLEXURAL STRENGTH ANALYSIS}

$314 \quad \mathbf{S 8}$ and $\mathbf{S 9}$ represents the stress-strain and load-displacement graphs respectively for flexural specimens using three-point bending method. The laminate L-4 withstands a highest flexural load of $348 \mathrm{~N}$ and least amount of flexural load was obtained for L-2 laminate. The peak flexural loads for laminates L-5 and L-6 falls to $263 \mathrm{~N}$ and $244 \mathrm{~N}$ respectively because of increase in filler concentration by the amount of $4 \%$ and $6 \%$. The laminate L-1 has a capability to withstand slightly higher load of $131 \mathrm{~N}$ as opposed to laminate L-2. During the observations of load-displacement curve, the laminate L-2 material failure occurred at less flexural load and then the displacement goes on increasing with decreasing load with long time duration as compared to other laminates.

The flexural strength and flexural modulus for different laminates are characterized in Figure

4 (a) and (b). The flexural strength indicated better adhesive properties between fiber-matrix with the filler material. Among all the laminates, the hybridized laminate with $2 \%$ pp (L-4) filler material had highest flexural strength of $287.84 \mathrm{MPa}$ and moderate flexural modulus of 6.42 GPa. The least amount of flexural strength (76.97 MPa) and modulus (3.36 GPa) were observed in L-2 laminate which was made of 4 layers of kevlar fabrics. The pure sisal fiber reinforced laminate (L-1) envied a flexural strength of $108.82 \mathrm{MPa}$ and modulus of $6.4 \mathrm{GPa}$ while, the hybridized 2 layered sisal and 2 layered kevlar laminate (L-3) withstands a flexural strength of $259.63 \mathrm{MPa}$ and modulus of $6.2 \mathrm{GPa}$. Further increased filler concentration by $4 \%$ and 6\% reduced the flexural strength by $217.55 \mathrm{MPa}$ and 202.04 MPa respectively, at the same time the modulus value was elevated to $7.4 \mathrm{GPa}, 8.2 \mathrm{GPa}$ for L-5 and L-6 laminates respectively. Hence by these observations the flexural modulus was increased with increase in filler concentration and the laminate L-4 with $2 \%$ filler gives optimum flexural properties. 


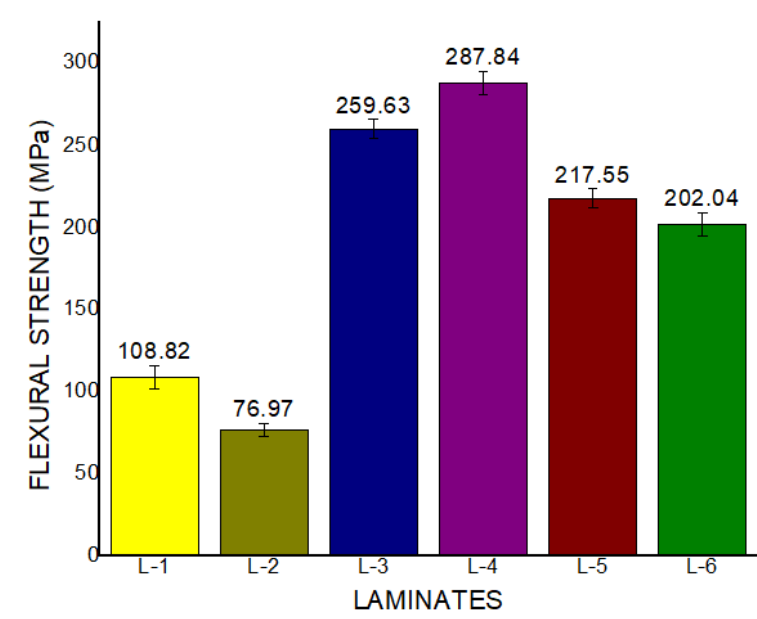

(a)

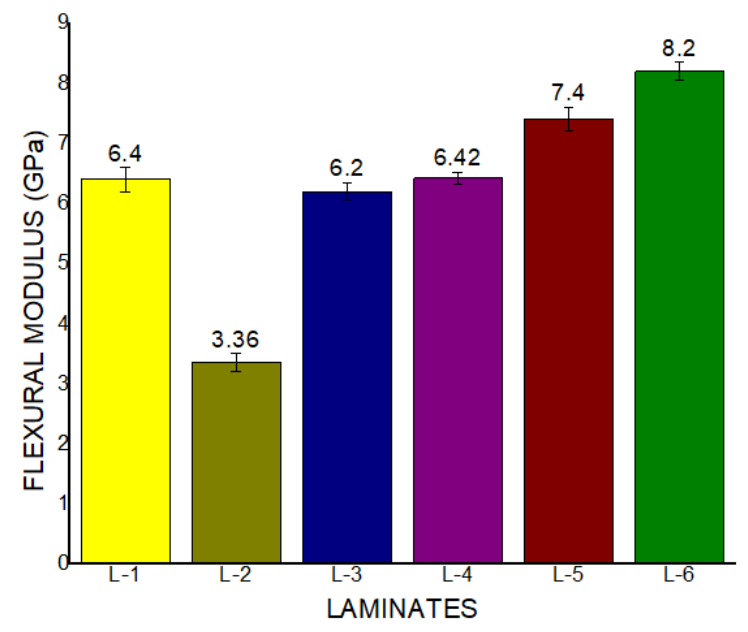

(b)

Figure 4. Flexural test results of the laminates: (a) Flexural strength (b) Flexural modulus

\section{IMPACT STRENGTH ANALYSIS}

The impact studies were conducted to determine the bonding strength of the fiber and matrix with the filler material. The impact strength $\left(\mathrm{kJ} / \mathrm{m}^{2}\right)$ of the different laminates is presented in

Figure 5. The impact properties depend on the various parameters like stacking sequence, fiber matrix bonding, nature of the fiber material and geometry of the composites. The impact strength was calculated using the equation (vii). The laminate L-2 has higher impact strength of $61.68 \mathrm{~kJ} / \mathrm{m}^{2}$ as compared to other laminates which was due to higher stiffness of the kevlar fabric. The lower impact strength was found in laminate L-1 which has only sisal fabric reinforcement. The hemicellulose contents and less stiffness value resulted in deprived impact strength. The natural and synthetic reinforced composite (L-3) has impact strength of $36.75 \mathrm{~kJ} / \mathrm{m}^{2}$. Further as the filler concentration increases in hybridized composites resulted in decreased impact strength of $31.5 \mathrm{~kJ} / \mathrm{m}^{2}(\mathrm{~L}-4), 28.35 \mathrm{~kJ} / \mathrm{m}^{2}(\mathrm{~L}-5)$ and $24.93 \mathrm{~kJ} / \mathrm{m}^{2}$ (L-6). This was mainly due to the presence of filler material which reduces the compatibility of fibermatrix interface and the adhesive nature between reinforcement and matrix phase. 


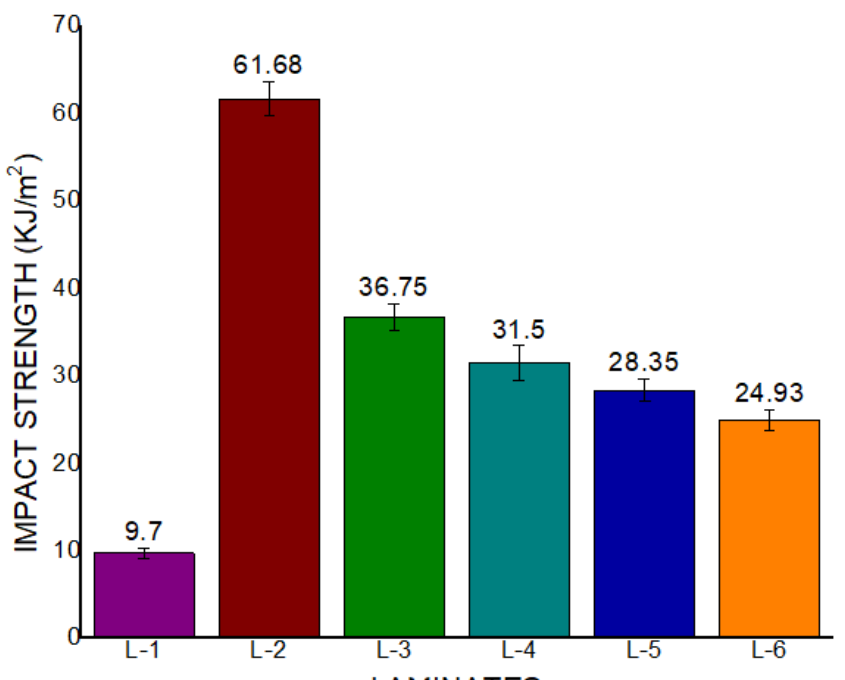

LAMINATES

Figure 5. Impact strength of composites

\section{ILSS STUDIES}

The ILSS studies follows the flexural test method with shorter span length. The stress v/s strain plots for ILSS specimens are shown in S10. The purpose of this test was to analyze the bonding between the fibers and matrix and also to identify the breaking load of the specimen. The load-displacement plot for different composite laminates are presented in S11. The laminate L-2 withstands a lowest breaking load of $139 \mathrm{~N}$ in which failure of specimens occurs by means breaking and bending of laminated fibers at lesser load capacity, whereas the laminate L-1 containing sisal reinforcement achieves higher breaking load of $232 \mathrm{~N}$ which was higher than the L-2 and thus indicating the strong bond between the fibers. The hybridized laminate L-3 attains a load of $367 \mathrm{~N}$ which was higher than both the laminates L-1 and L-2. The load withstanding capacity was more in $2 \%$ pp filled composite i.e., $425 \mathrm{~N}$ and was higher among all the laminates prepared and further filler increased laminates L-5 and L6 resulted in breaking load of $399 \mathrm{~N}$ and $419 \mathrm{~N}$ respectively. The ILSS for the different laminates are presented in Figure 6. The highest shear strength was achieved in L-4 (10.63 
$\mathrm{MPa}$ ) because of the existence of the filler particles which opposed the shearing of laminates and hence enhanced strength of the laminates. The laminate L-2 showed a strength value of and 10.49 $\mathrm{MPa}$ respectively. Hence it is concluded that the addition of fillers to hybridized composite enhances the ILSS property.

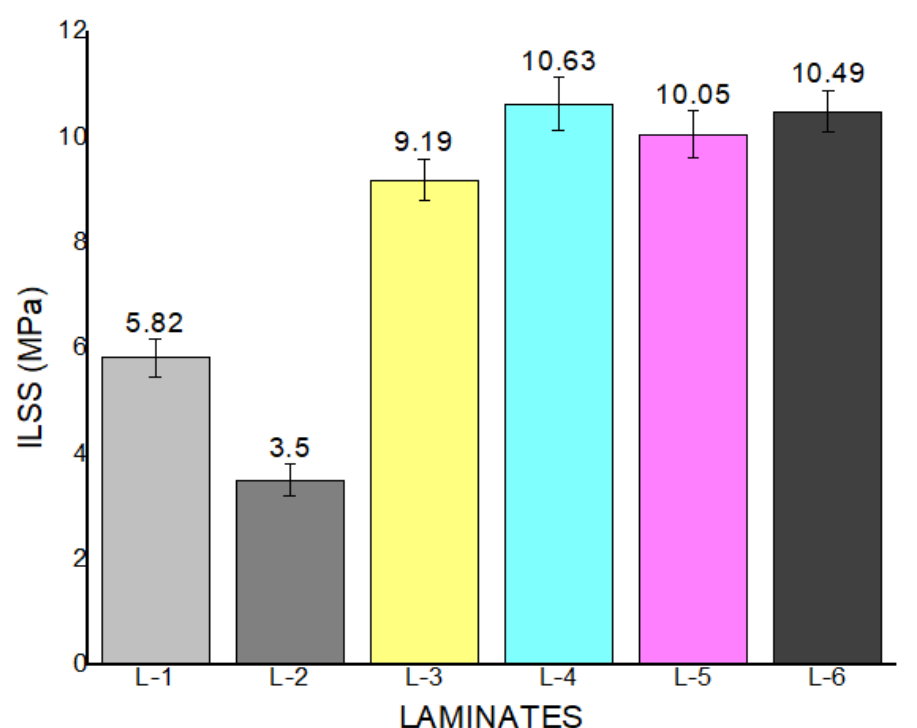

LAMINATES

$377 \quad$ Figure 6. ILSS of different composite laminates

\section{HARDNESS STUDIES}

Figure 7 indicates the comparison of hardness values for different laminates using Shore-D durometer. The laminate L-6 which consists of hybrid layers of sisal and kevlar with $6 \%$ filler material gives highest hardness value of 76 and $4 \%, 2 \%$ filler filled composite exhibits hardness values ranging 73 and 71 respectively. This shows the filler material resistance against the material deformation and the indentation of laminates. The other laminates L-1, L-2 and L-3 hardness values ranged 55, 70 and 67 respectively. The natural sisal reinforced composite showed least hardness value due to its softness which resulted in easier material deformation. 




Figure 7. Hardness value for different laminates

390

391

\section{WATER ABSORPTION STUDIES}

The specimens gain weight due to absorbing of water molecules after immersion. The test was conducted for a duration of 28 days in normal and distilled water with intervals of 7 days. The weights before and after duration in both the conditions are tabulated in Table 4 and 5. The test results reveal that the water absorption percentage is more in L1laminatewhich is composed of pure sisal fabric. The less amount of water absorption is seen in laminate L-2 which contains 4 layers of kevlar fabrics. The plane hybridized composites exhibit less absorption capacity as opposed to filler filled laminate because of the natural fillers cellulose based content. The specimen's water absorption was more in normal water as compared to distilled water.

Table 4. Water absorption percentage in distilled water

\begin{tabular}{|l|l|l|l|l|l|}
\hline Laminates & Weight of the specimens & \multicolumn{3}{l|}{ Percentage increase in weights } \\
\cline { 3 - 6 } & Before immersion (g) & Day 7 & Day 14 & Day & Day 28 \\
& & & & $\mathbf{2 1}$ & \\
\hline L-1 & 4.286 & 7.12 & 9.25 & 13.78 & 16.69 \\
\hline
\end{tabular}




\begin{tabular}{|l|l|l|l|l|l|}
\hline L-2 & 3.776 & 2.36 & 5.02 & 8.26 & 11.53 \\
\hline L-3 & 3.987 & 3.27 & 6.38 & 10.24 & 13.92 \\
\hline L-4 & 4.126 & 3.38 & 6.95 & 10.97 & 14.02 \\
\hline L-5 & 4.187 & 3.76 & 7.23 & 11.26 & 14.43 \\
\hline L-6 & 4.215 & 4.01 & 7.91 & 11.95 & 14.93 \\
\hline
\end{tabular}

402

Table 5. Water absorption percentage in normal water

\begin{tabular}{|l|l|l|l|l|l|}
\hline \multirow{2}{*}{ Laminates } & Weight of the specimens & \multicolumn{3}{l}{ Percentage increase in weights } \\
\cline { 3 - 6 } & Before immersion (g) & Day 7 & Day 14 & Day & Day 28 \\
& & & & $\mathbf{2 1}$ & \\
\hline L-1 & 4.395 & 6.9 & 9.65 & 13.98 & 17.08 \\
\hline L-2 & 3.721 & 2.64 & 5.56 & 8.95 & 12.01 \\
\hline L-3 & 3.921 & 3.26 & 7.02 & 10.98 & 14.03 \\
\hline L-4 & 4.105 & 3.86 & 7.27 & 11.23 & 14.82 \\
\hline L-5 & 4.196 & 4.03 & 8.12 & 12.12 & 14.96 \\
\hline L-6 & 4.296 & 4.4 & 8.3 & 12.35 & 15.56 \\
\hline
\end{tabular}

404

405

406

SEM STUDIES

407 The SEM studies was carried out for the analysis of composite fractured surfaces for the examination of fiber-matrix bonding interface. The scanned SEM image was coated with gold layer before image capturing. The tensile fractured SEM images of sisal/kevlar and filler filled hybrid epoxy composites are shown in Figure 10. The sisal fiber yarns (L-1) bonded

411 with matrix material is shown in Figure 10 (a). It is observed that smoother surfaces can be 412 found in the structure and some resin poor spaces were found around the yarns. Figure 10 (b) 
indicates the micro image of kevlar fiber reinforced composite laminate (L-2) and broken

414 kevlar yarns are spotted in the figure. The voids were found on the surface of the specimen and surface cracks were found due to less adhesive nature between fiber and the matrix.

416 Figure 10 (c) indicates the fractured surface of hybridized laminate (L-3) where fiber yarns

417 breakage occurred and indicated the better adhesion between the fibers and matrix. Some

418 small micro pores were observed in the image due to air bubbles which occurs commonly in

419 hand lay-up process. Figure 10 (d) indicates the existence of strong bonding between fiber-

420 matrix and the filler material. Lesser voids, fiber breakage was observed along with the fiber

421 pullout. The loosely spotted fiber area was observed due to weak strength between fiber and

422 the matrix. The filler particles agglomeration with the matrix was observed in Figure $\mathbf{1 0}$ (e).

423 Sometimes the space was found around the yarns because of fiber diameter and alignment of

424 fabric manually. The cell wall structures were found where the fibers yarns are completely

425 pulled out from the matrix (Figure $10(\mathbf{f})$ ). Fiber tearing occurs during the tensile loading in

426 the poor strengthened area.

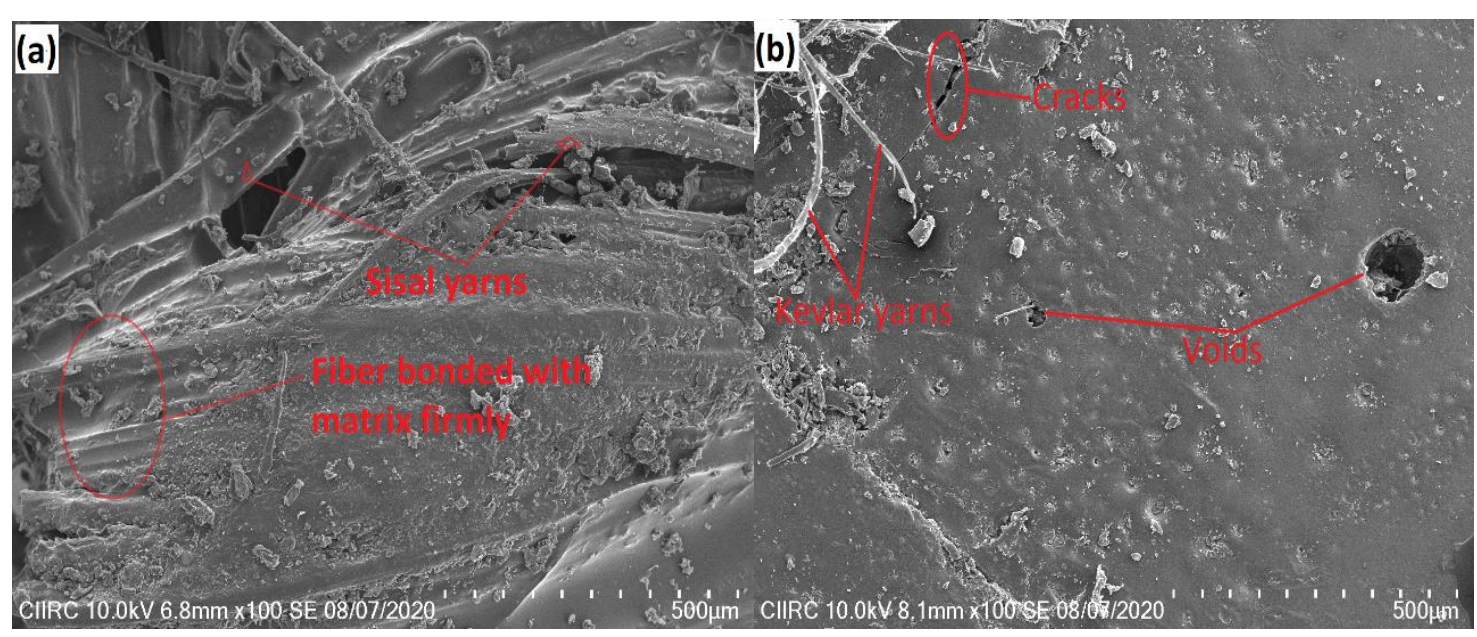



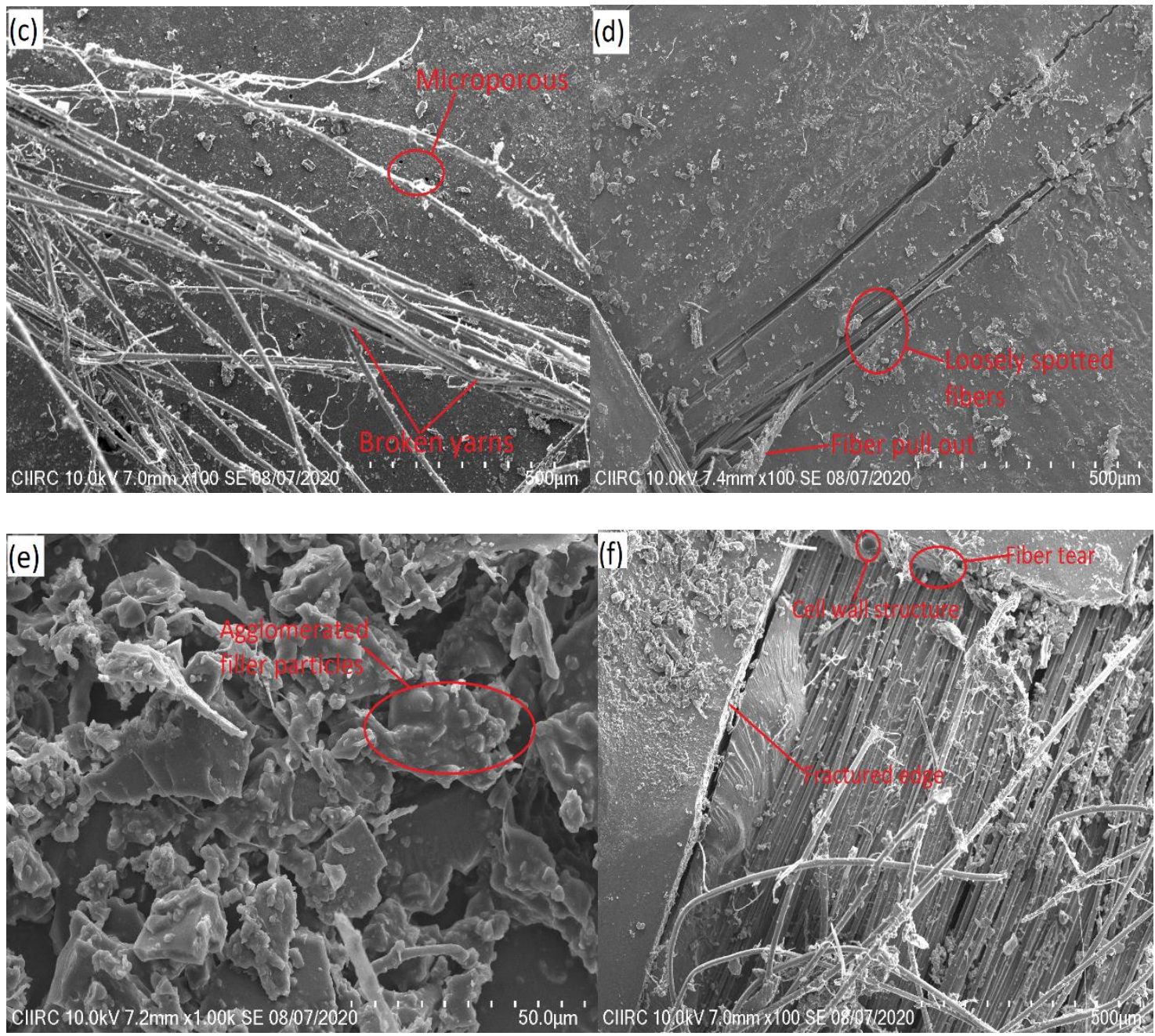

Figure 10. SEM micrographs of tensile fractured sufaces:(a) Laminate L-1; (b) Laminate L-

2; (c) Laminate L-3; (d) Laminate L-4; (e) Laminate L-5; (f) Laminate (L-6)

The fractured flexural specimens are presented in Figure 11. It was observed that during

flexural loading the fibers bending occurs whereas in some cases the fiber yarns pulled out from the matrix phase and leaves the space which are mentioned as fiber yarn walls and are indicated in Figure 11 (a). The fractured edges are represented in Figure 11 (b). Due to the

437 lesser interfacial adhesion, the fiber pullout occurred, and resin rich area was spotted in 438 Figure 11 (c) and (d) respectively. The weaker sections of the composite results in pull out of 439 the fibers from the matrix phase (Figure 11 (e) and (f)). As compared to tensile specimens 440 the voids and loosely bonded fibers are less in flexural specimens. Especially the filler filled 
441 composite laminates exhibits less fiber breakage, crack propagation and higher adhesive 442 strength between fiber-matrix and the filler materials.

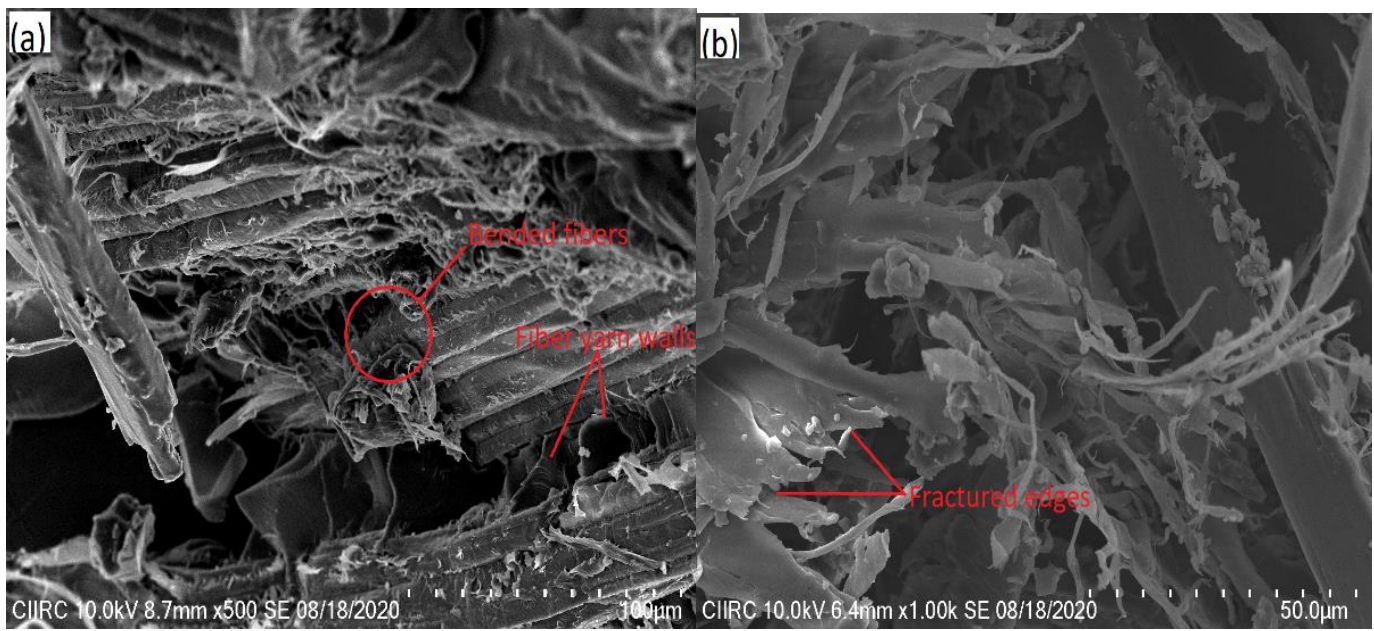

443
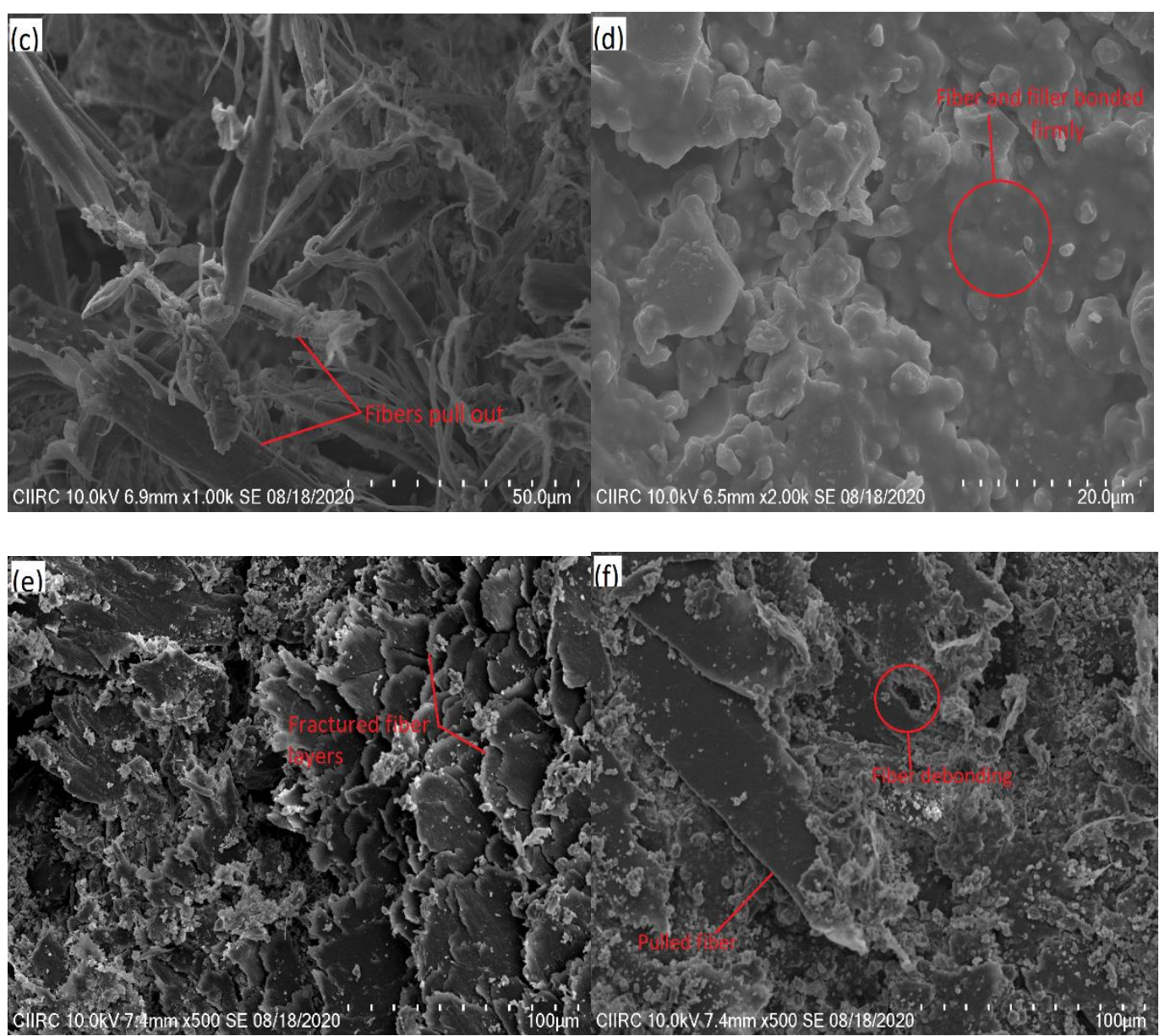

446 Figure 11. SEM morphology of flexural specimens: (a) Laminate L-1; (b) Laminate L-2; (c)

447 Laminate L-3; (d) Laminate L-4; (e) Laminate L-5; (f) Laminate (L-6) 


\section{CONCLUSIONS}

450 In this experimental work, sisal/ kevlar fabrics were successfully reinforced with epoxy 451 matrix and were filled with $2 \%, 4 \%$ and $6 \%$ of pongamia pinnata to come up with a novel 452 material in the field of natural fiber polymer composites. Manual hand lay-up method was 453 employed in fabrication of the hybrid composite laminates and those prepared laminates were scrutinized for their different physical, mechanical and microstructural properties. The volume fraction studies deliberate that the L-6 laminates show lesser voids among all the laminates due to the incorporation of kevlar fabric and filler material in natural sisal fabrics. The superior tensile, flexural, impact and hardness properties of the prepared sisal/kevlar filled pongamia pinnata reinforced hybrid composite laminates justifies their utilization in some medium load structural applications. The water absorption study also exemplifies that the addition of natural filler will significantly affect in the moisture resistance behaviour of the prepared composites. The SEM morphology analysis reveals the strong bonding in fillerbased composites with lesser void contents which in turn envied the better adhesion properties between fabrics and epoxy matrix impacting in better physico-mechanical properties. Hence from all the test observations, the hybrid composite with $2 \%$ filler gives optimum results and hence recommended in some applications such as bicycle frames, helmets, car door panels, computer spare parts, mobile cases, mats and office cubicle frames.

\section{ACKNOWLEDGEMENTS}

The authors would like to extend their sincere appreciation to the Researchers Supporting Project for funding this work through Research Number (RSP-2020/138), King Saud University, Riyadh, Saudi Arabia. 


\section{Declarations}

475 Funding: The authors would like to extend their sincere appreciation to the Researchers 476 Supporting Project for funding this work through Research Number (RSP-2020/138), King 477 Saud University, Riyadh, Saudi Arabia.

478 Conflicts of interest/Competing interests: None

479 Availability of data and material: Not applicable

480 Code availability: Not applicable

481

482

\section{REFERENCES}

483

484

Amir SMM, Sultan MTH, Jawaid M, et al (2019) Nondestructive testing method for Kevlar and natural fiber and their hybrid composites. In: Durability and Life Prediction in Biocomposites, Fibre-Reinforced Composites and Hybrid Composites. Elsevier, pp 367388

Arpitha GR, Sanjay MR, Senthamaraikannan P, et al (2017) Hybridization effect of sisal/glass/epoxy/filler based woven fabric reinforced composites. Exp Tech 41:577-584

Asim M, Jawaid M, Saba N, et al (2017) Processing of hybrid polymer composites-a review. In: Hybrid Polymer Composite Materials. Elsevier, pp 1-22

Damião Xavier F, Santos Bezerra G, Florentino Melo Santos S, et al (2018) Evaluation of the simultaneous production of xylitol and ethanol from sisal fiber. Biomolecules 8:2

Dinesh S, Kumaran P, Mohanamurugan S, et al (2020) Influence of wood dust fillers on the mechanical, thermal, water absorption and biodegradation characteristics of jute fiber epoxy composites. J Polym Res 27:9

Elanchezhian C, Ramnath BV, Ramakrishnan G, et al (2018) Review on mechanical properties of natural fiber composites. Mater Today Proc 5:1785-1790 
Fu S, Yu B, Tang W, et al (2018) Mechanical properties of polypropylene composites reinforced by hydrolyzed and microfibrillated Kevlar fibers. Compos Sci Technol $163: 141-150$

Gowda TGY, Sanjay MR, Bhat KS, et al (2018) Polymer matrix-natural fiber composites: An overview. Cogent Eng 5:1446667

HPS AK, Masri M, Saurabh CK, et al (2017) Incorporation of coconut shell based nanoparticles in kenaf/coconut fibres reinforced vinyl ester composites. Mater Res Express 4:35020

Jani SP, Kumar AS, Khan MA, Kumar MU (2016) Machinablity of hybrid natural fiber composite with and without filler as reinforcement. Mater Manuf Process 31:1393-1399

Jothibasu S, Mohanamurugan S, Vijay R, et al (2020) Investigation on the mechanical behavior of areca sheath fibers/jute fibers/glass fabrics reinforced hybrid composite for light weight applications. J Ind Text 49:1036-1060. https://doi.org/10.1177/1528083718804207

Madhu P, Sanjay MR, Senthamaraikannan P, et al (2019) A review on synthesis and characterization of commercially available natural fibers: Part II. J Nat Fibers 16:25-36

Matykiewicz D, Barczewski M, Knapski D, Skórczewska K (2017) Hybrid effects of basalt fibers and basalt powder on thermomechanical properties of epoxy composites. Compos Part B Eng 125:157-164

Mohan N, Natarajan S, KumareshBabu SP (2012) The role of synthetic and natural fillers on three-body abrasive wear behaviour of glass fabric-epoxy hybrid composites. J Appl Polym Sci 124:484-494

Naveen J, Jawaid M, Amuthakkannan P, Chandrasekar M (2019) Mechanical and physical properties of sisal and hybrid sisal fiber-reinforced polymer composites. In: Mechanical and physical testing of biocomposites, fibre-reinforced composites and hybrid 
524

525

Ojha S, Raghavendra G, Acharya SK (2014) A comparative investigation of bio waste filler (wood apple-coconut) reinforced polymer composites. Polym Compos 35:180-185

Prabu VA, Manikandan V, Uthayakumar M, Kalirasu S (2012) Investigations on the mechanical properties of red mud filled sisal and banana fiber reinforced polyester composites. Mater Phys Mech 15:173-179

Praveenkumara J, Madhu P, Yashas Gowda TG, Pradeep S Studies on Mechanical Properties of Bamboo/Carbon Fiber Reinforced Epoxy Hybrid Composites Filled with SiC Particulates

Qi HJ, Joyce K, Boyce MC (2003) Durometer hardness and the stress-strain behavior of elastomeric materials. Rubber Chem Technol 76:419-435

Rajulu AV, Chary KN, Reddy GR, Meng YZ (2004) Void content, density and weight reduction studies on short bamboo fiber-epoxy composites. J Reinf Plast Compos 23:127-130

Rana RS, Rana S, Purohit R (2017) Characterization of properties of epoxy sisal/glass fiber reinforced hybrid composite. Mater Today Proc 4:5445-5451

Sanjay MR, Arpitha GR, Laxmana Naik L, et al (2016) Studies on mechanical properties of banana/e-glass fabrics reinforced polyester hybrid composites. J Mater Environ Sci $7: 3179-3192$

Sanjay MR, Madhu P, Jawaid M, et al (2018) Characterization and properties of natural fiber polymer composites: A comprehensive review. J Clean Prod 172:566-581

Sanjay MR, Siengchin S, Parameswaranpillai J, et al (2019) A comprehensive review of techniques for natural fibers as reinforcement in composites: Preparation, processing and characterization. Carbohydr Polym 207:108-121. https://doi.org/10.1016/j.carbpol.2018.11.083 
548 Shakuntala O, Raghavendra G, Samir Kumar A (2014) Effect of filler loading on mechanical 549 and tribological properties of wood apple shell reinforced epoxy composite. Adv Mater $550 \quad$ Sci Eng 2014:

551 Sharma V, Meena ML, Kumar M (2020) Effect of filler percentage on physical and 552 mechanical characteristics of basalt fiber reinforced epoxy based composites. Mater 553 Today Proc

554 Singh H, Batra NK, Dikshit I (2020) Development of new hybrid jute/carbon/fishbone 555 reinforced polymer composite. Mater Today Proc

556 Swolfs Y, Gorbatikh L, Verpoest I (2014) Fibre hybridisation in polymer composites: a 557 review. Compos Part A Appl Sci Manuf 67:181-200

558 Thyavihalli Girijappa YG, Mavinkere Rangappa S, Parameswaranpillai J, Siengchin S (2019) 559 Natural Fibers as Sustainable and Renewable Resource for Development of Eco560 Friendly Composites: A Comprehensive Review. Front Mater 6:1-14. $561 \quad$ https://doi.org/10.3389/fmats.2019.00226

562 Vinod A, Sanjay MR, Siengchin S, Parameswaranpillai J (2020) Renewable and Sustainable 563 Biobased Materials: An Assessment on Biofibers, Biofilms, Biopolymers and 564 Biocomposites. J Clean Prod 258:120978. https://doi.org/10.1016/j.jclepro.2020.120978 


\section{Figures}

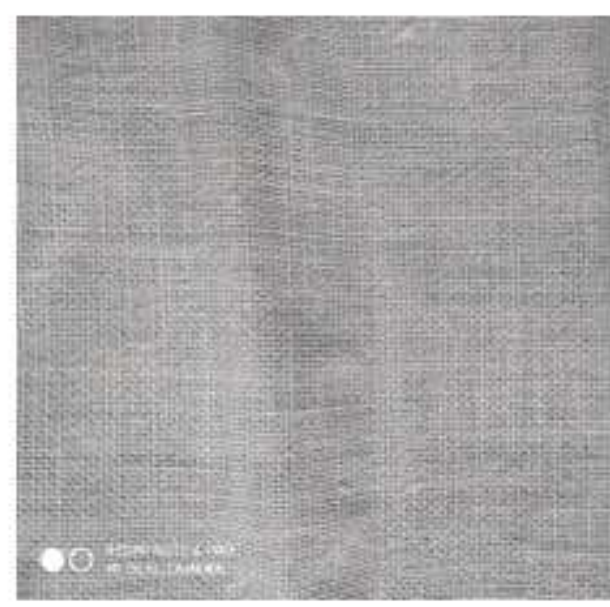

(a)

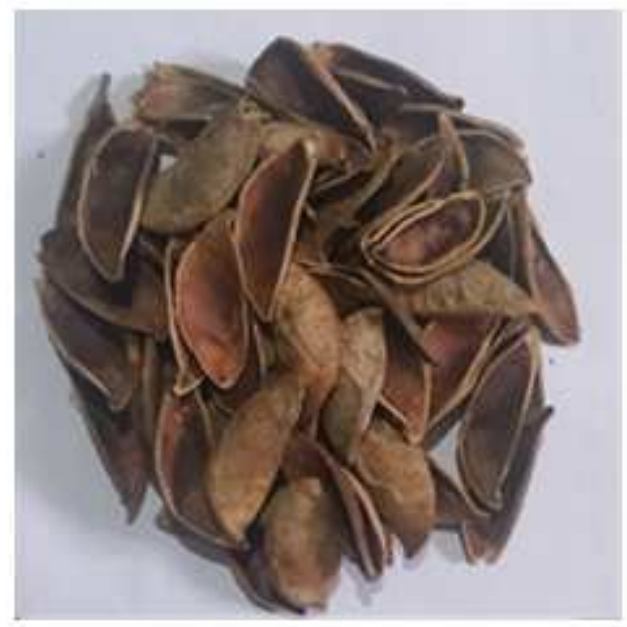

(c)

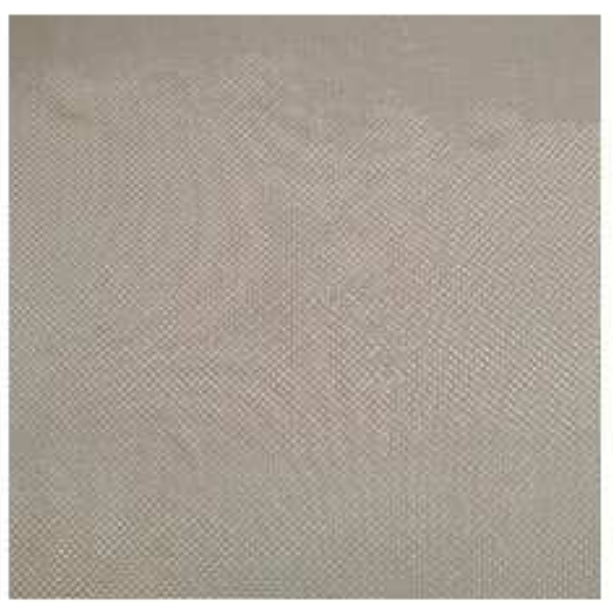

(b)

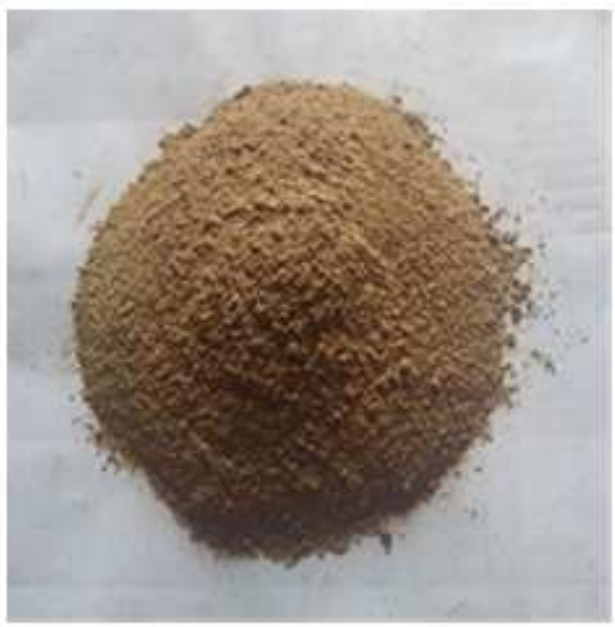

(d)

\section{Figure 1}

Materials used in the present study: (a) sisal fabric (b) kevlar fabric (c) Pongamia pinnata shells (d) Pongamia pinnata shells powder 

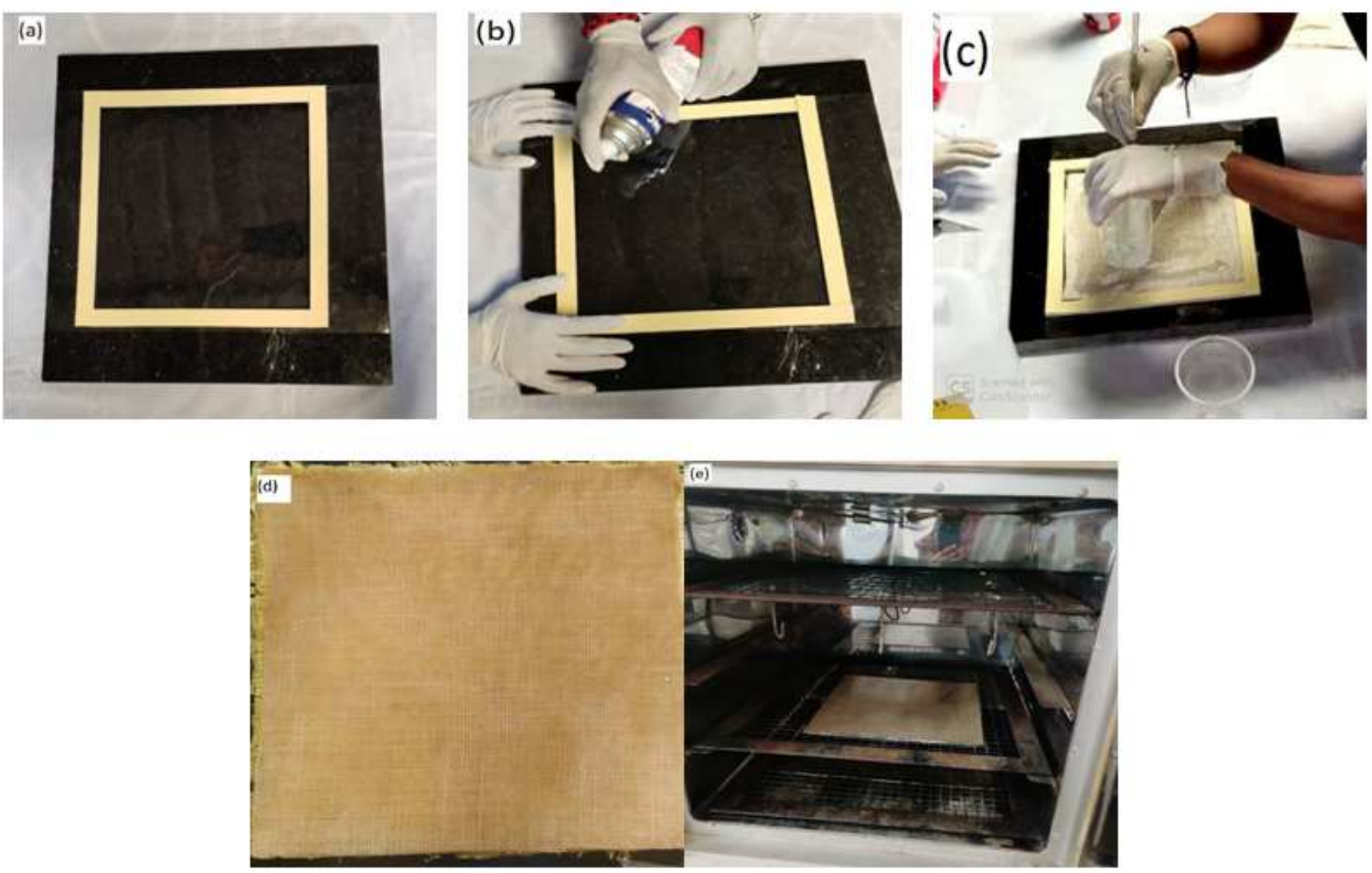

Figure 2

(a) Mold prepared using sealing tape (b) Silicone spray (c) Resin lay up (d) Fabricated laminate (e) Laminate curing in oven.

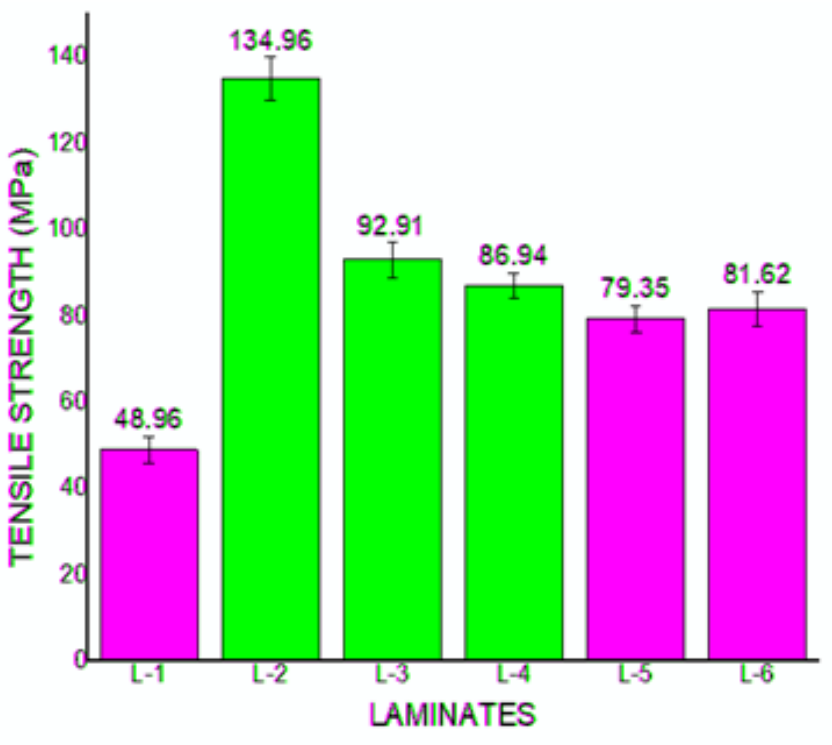

(a)

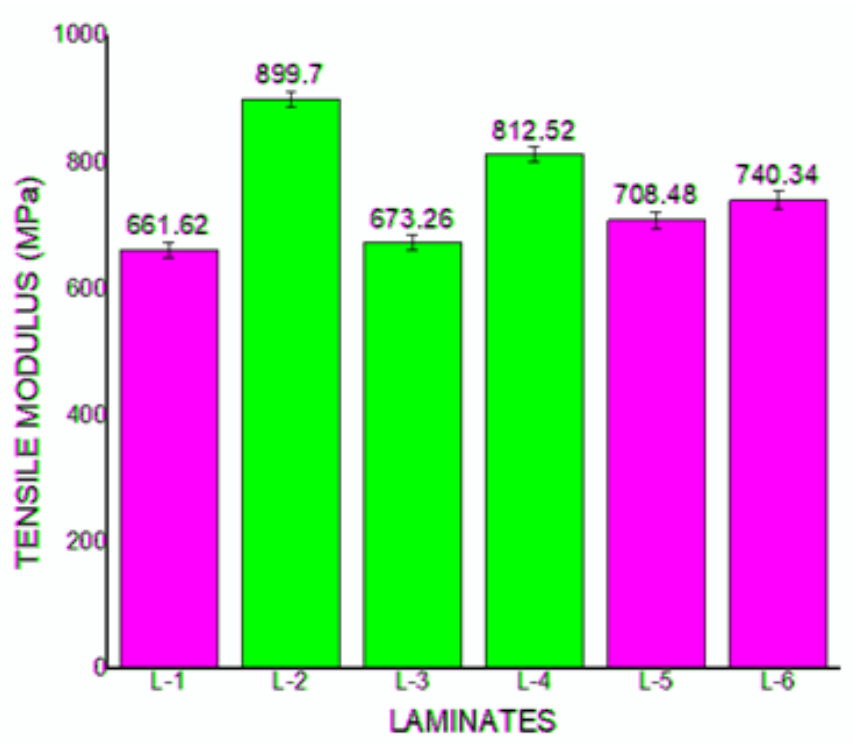

(b) 
Figure 3

Tensile test results of the laminates: (a) Tensile strength (b) Tensile modulus

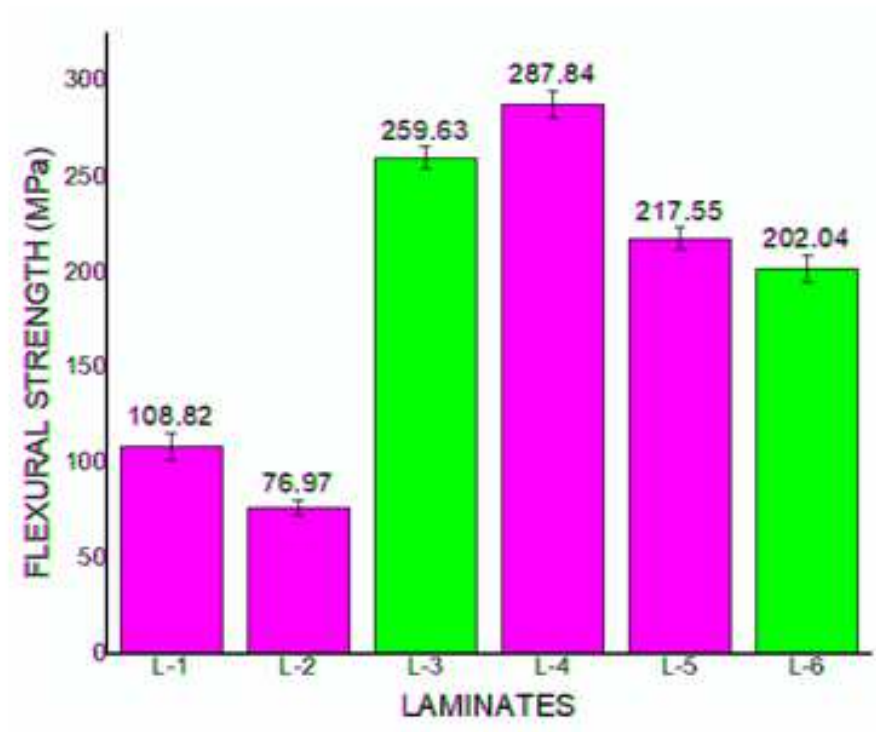

(a)

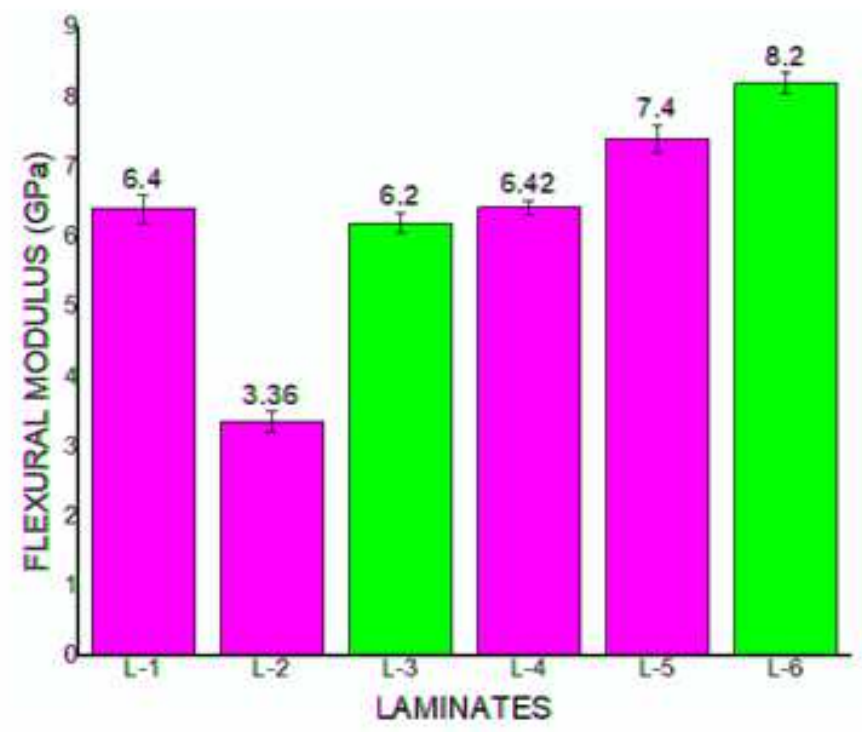

(b)

\section{Figure 4}

Flexural test results of the laminates: (a) Flexural strength (b) Flexural modulus

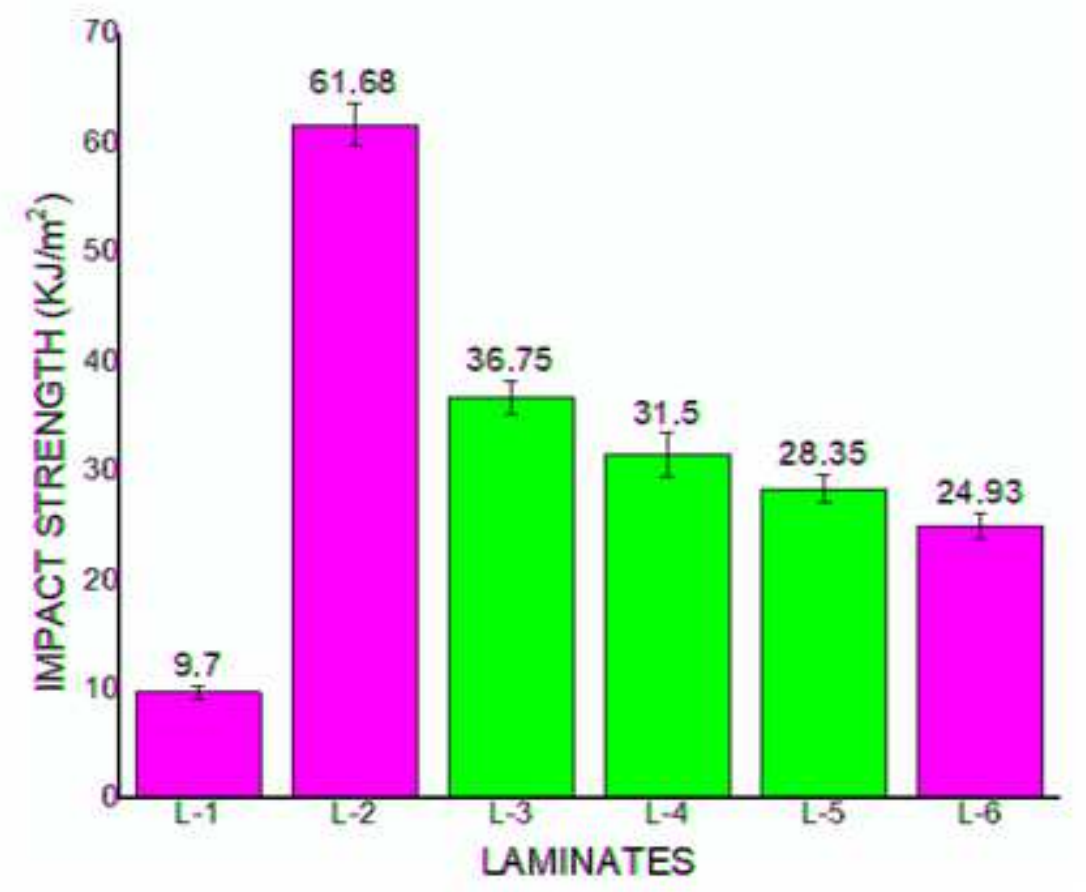

Figure 5 
Impact strength of composites

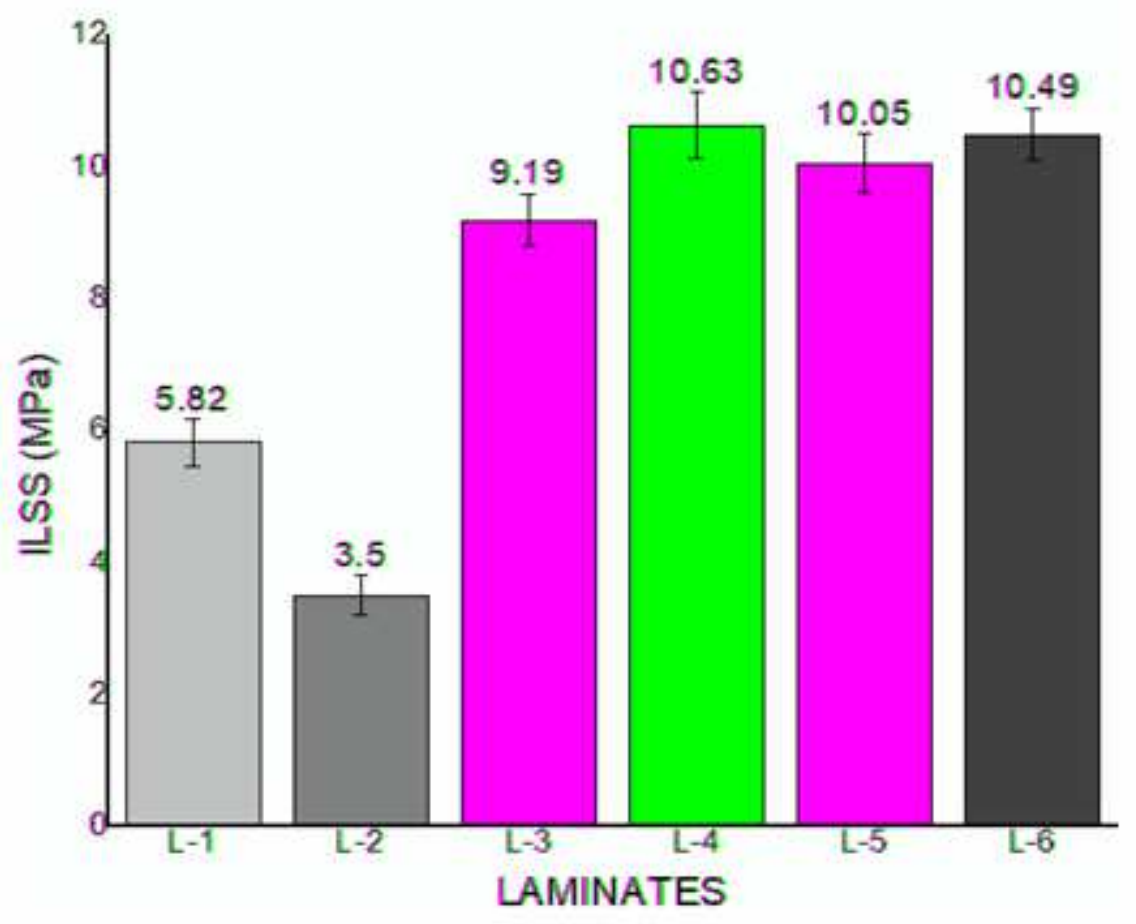

Figure 6

ILSS of different composite laminates

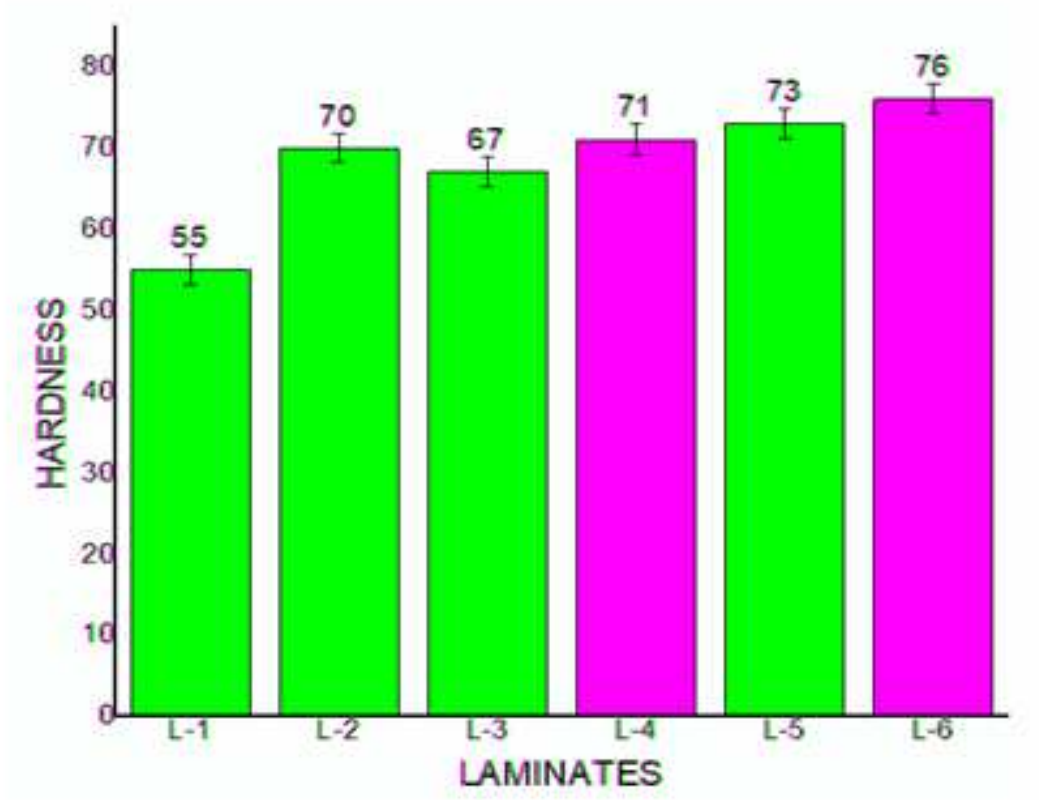

Figure 7

Hardness value for different laminates 

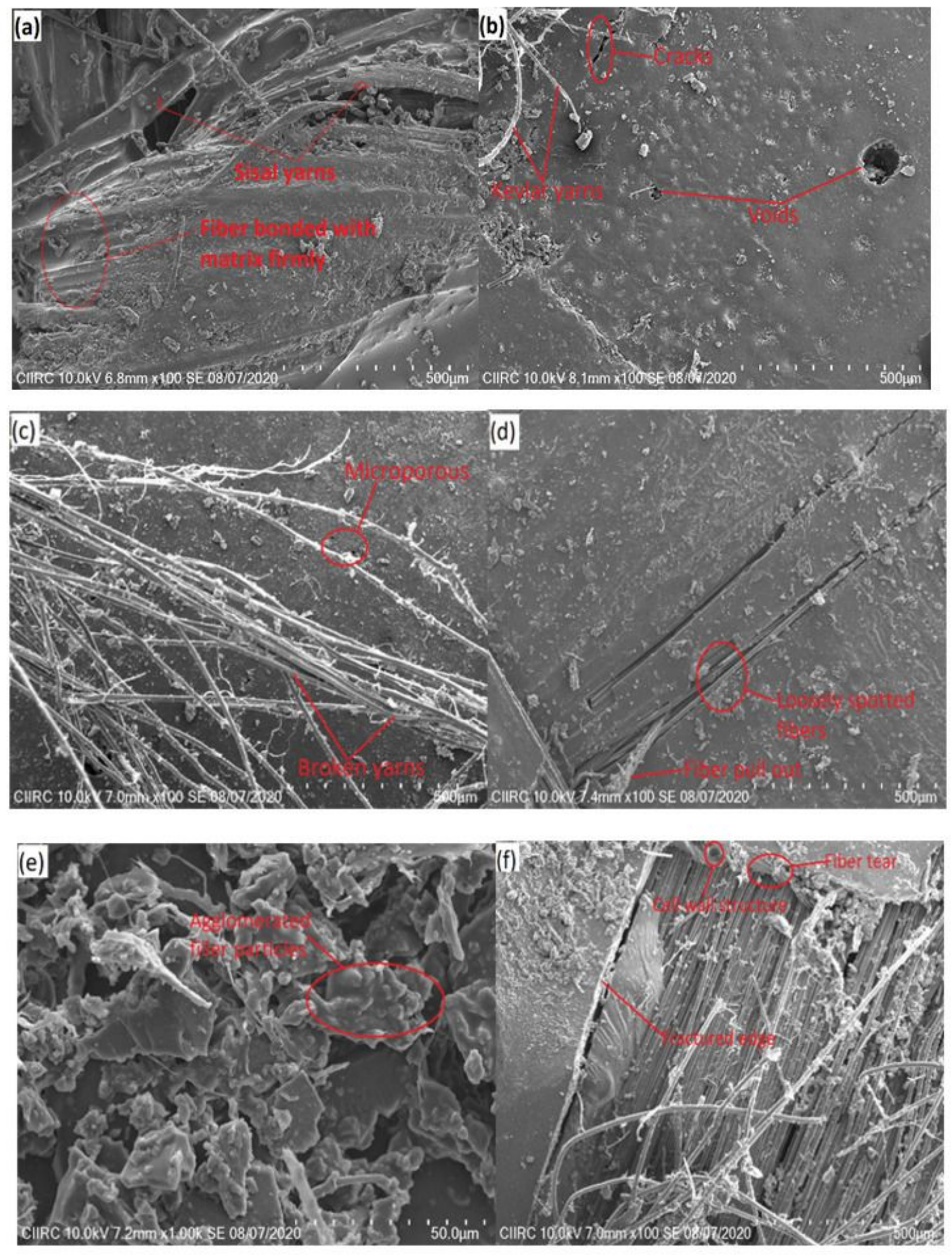

\section{Figure 8}

SEM micrographs of tensile fractured sufaces:(a) Laminate L-1; (b) Laminate L-2; (c) Laminate L-3; (d) Laminate L-4; (e) Laminate L-5; (f) Laminate (L-6) 

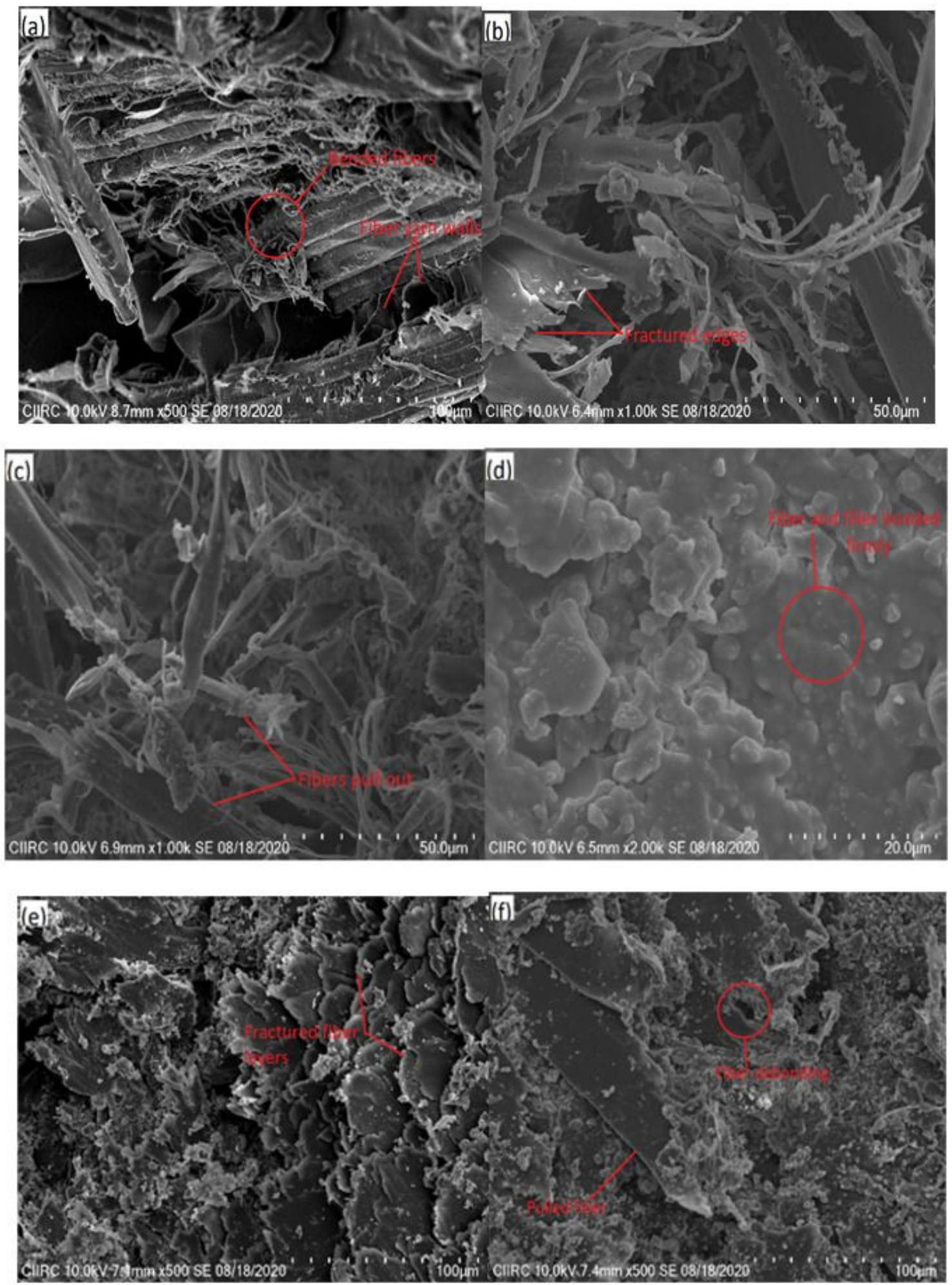

Figure 9

SEM morphology of flexural specimens: (a) Laminate L-1; (b) Laminate L-2; (c) Laminate L-3; (d) Laminate L-4; (e) Laminate L-5; (f) Laminate (L-6)

\section{Supplementary Files}


This is a list of supplementary files associated with this preprint. Click to download.

- SupplymentaryMaterials.docx 